\title{
LI. Experimental investigations on magnetic rotatory polarization in gases
}

\section{Henri Becquerel}

To cite this article: M. Henri Becquerel (1881) LI. Experimental investigations on magnetic rotatory polarization in gases, Philosophical Magazine Series 5, 12:77, 394-434, DOI: 10.1080/14786448108627128

To link to this article: http://dx.doi.org/10.1080/14786448108627128

曲 Published online: 28 Apr 2009.

Submit your article to this journal $\sqsubset x$

Џll Article views: 2

Q View related articles $₫$ 
If $\omega=0$, then $\Delta=0$; so that, corresponding to Cayley's theorem, "An odd-ordered determinant which is skew with respect to a zero diagonal vanishes," we have an exact counterpart, viz. "An odd-ordered determinant which is skew with respect to a zero centre vanishes." The latter, too, may be proved exactly like the former, viz. by multiplying the elements of every row by -1 , and thus showing that $\Delta=-\Delta$.

But, further, the product of the two determinants in (III.) is equal to

$$
(-1)^{3}\left|\begin{array}{lll|lll}
a_{1}-a_{7} & a_{2}-a_{6} & a_{3}-a_{5} & a_{1}+a_{7} & a_{2}+a_{6} & a_{3}+a_{5} \\
b_{1}-b_{7} & b_{2}-b_{6} & b_{3}-b_{5} & b_{1}+b_{7} & b_{2}+b_{6} & b_{3}+b_{5} \\
c_{1}-c_{7} & c_{2}-c_{6} & c_{3}-c_{5} & c_{1}+c_{7} & c_{2}+c_{6} & c_{3}+c_{5}
\end{array}\right|,
$$

and therefore, by Zehfuss's theorem, is equal to

$$
(-1)^{3}\left|\begin{array}{cccccc}
a_{1} & a_{2} & a_{3} & a_{5} & a_{6} & a_{7} \\
b_{1} & b_{2} & b_{3} & b_{5} & b_{6} & b_{7} \\
c_{1} & c_{2} & c_{3} & c_{5} & c_{6} & c_{7} \\
c_{7} & c_{6} & c_{5} & c_{3} & c_{2} & c_{1} \\
b_{7} & b_{6} & b_{5} & b_{3} & b_{2} & b_{1} \\
a_{7} & a_{6} & a_{5} & a_{3} & a_{2} & a_{1}
\end{array}\right|,
$$

that is to say, is equal to the centre-skew determinant obtained from $\Delta$ by deleting the middle row and middle column. Hence the theorem-A centre-skew determinant of odd order is not altered by making all the elements of the middle row and middle column zero with the exception of the centre element.

Instead of deducing this from (III.) we might reverse the order, viz. prove the theorem just enunciated by expanding $\Delta$ according to binary products of the elements of the middle row and middle column, and then by means of this theorem establish (III.).

Beecheroft, Bishopton, N. B., October 8,1881 .

LI. Experimental Investigations on Magnetic Rotatory Polarization in Gases. By M. Henri Becquerel.

[Concluded from p. 324.]

Discussion of the Sources of Error: Corrections.

TN measurements so delicate as these about to be recorded, it 1 was of the highest importance that the effect of the various disturbing causes proceeding from the apparatus itself should be most carefully studied and measured. Although the corrections which it was necessary to make in the results observed were very small, yet, as they were of the same order 
of magnitude as the latter, it was essential to determine them with the greatest accuracy.

They may be grouped in the following manner :-

I. Variations in electromagnetic intensity.

II. Want of homogeneity in the luminous source.

III. Magnetic rotations caused by the glasses and the glass of the mirrors interposed in the course of the luminous rays.

IV. Corrections due to variations of temperature in the gases.

$\mathrm{V}$. Displacement of the luminous point.

I. Variations in Electromagnetic Intensity.-We have already stated that the heating of the conductors during the passage of the electric current and the operation of the pile gave rise to a regular variation in the electromagnetic intensity, and that the intensity of the induced current, which is in proportion to that of the principal electric current, was measured repeatedly. The numbers obtained enabled the observed results to be reduced by a simple proportion to what they would be if the intensity remained constant. The accuracy of these numbers will therefore depend on the precision with which the intensities are measured. We made use of a sine-compass placed at 10.50 metres from the middle of the large solenoid in the apparatus. At this distance the magnetic influence on the compass was still sensible, and deflected the needle abont $10^{\prime}$, either to the right or left, according to the direction of the current in the bobbins. In order to eliminate this disturbing element, each determination of the intensity consisted of two successive measurements, made by reversing the direction of the electric current in the bobbins; and the average of the two deviations obtained was taken as the definitive measurement.

During the course of a series of observations these determinations were repeated very frequently, every ten or fifteen minutes; and it is certain that, for the measurements included in these intervals of time, the numbers obtained by interpolation gave the intensity of the current with a precision equal to that of direct determinations.

The deviations of the compass varied between $25^{\circ}$ and $22^{\circ}$; the total variation from morning to evening for the same series scarcely amounted to $2^{\circ}$. All the results were reduced to what they would have been if the deviation had been constantly $24^{\circ}$. The error in the measurements of the angles did not exceed $1^{\prime}$; so that, with respect to the intensities, the error could not amount to 0.001 of their value. This accuracy 
is greater than that of the numbers obtained for the magnetic rotations of the gases.

II. Want of Homogeneity in the Luminous Source.-A shaded polariscope, formed of a divided nicol, such as the one employed by us, might be used for studying light of any colour whatever, provided that the luminous rays of different wave-lengths experienced the same action. Under the influence of magnetism, on the contrary, the planes of polarization of the different rays are unequally deflected, the image from the polariscope is tinged with various colours, and before any measurements are possible it is necessary to make use of a monochromatic source of light. On the other hand, our apparatus needed an extremely brilliant source of light, on account of the very long distance generally traversed by the luminous rays before reaching the eye: the passage through the glasses and the successive reflections are all causes of loss of light; and equality of tint is obtained by almost extinguishing the images, and preserving not more than about $0.0019^{*}$ of the intensity of the incident ray.

I first attempted to direct the blast of a compound blowpipe onto a large piece of fused chloride of sodium. This light is extremely bright for a moment; but the salt begins to melt very rapidly, without giving time for a measurement to be completed by reversing the direction of the electric current. It is true that the light might be maintained by progressively displacing the piece of chloride of sodium, which melts only at one point; but this gives rise to a very grave cause of error: the luminous point is displaced; and this displacement causes corresponding deviations of the plane of polarization, which completely disturb the phenomena due to magnetic influence. I was therefore obliged to relinquish the employment of this source of light.

When the piece of chloride of sodium just spoken of is replaced by a piece of quicklime, the light emitted by the incandescent lime is composed of nearly all the rays which form the visible part of the solar spectrum, but the luminous point has the advantage of remaining almost perfectly fixed.

As the rotations observed in the apparatus are very slight, the images are only very faintly coloured, and the measurements of equality of tint can be made with great exactitude. They become still clearer if a coloured screen, which allows

* This number is obtained as follows :-The position of the analyzer which corresponds to the equality of tint is at $2^{\circ} 30^{\prime}$ from those which correspond to the extinction of each half of the image from the polariscope. In this position, therefore, the luminous intensity is represented by $\cos ^{2} 87^{\circ} 30^{\prime}=0.001900$, the intensity of the incident ray being taken as unity. 
only a narrow portion of the spectrum to pass, is placed between the source of light and the polariscope.

In this point of view, the want of homogeneity in the source of light causes only a slight perturbation in the appreciation of the equality of tint of the two halves of the image ; nevertheless an imperfect knowledge of the wave-length of the luminous rays which reach the eye causes a serious uncertainty, which it is most desirable to obviate.

In fact, it usually happens, as will be shown later, that the magnetic rotations of the planes of polarization of luminous rays of different wave-lengths traversing a gaseous column, are very nearly in the inverse ratio of the squares of their wave-lengths. The slightest variation, then, in the nature of the rays, of which the equality of tint is being estimated, modifies the size of the corresponding magnetic rotation very considerably; and our apparatus was sufficiently sensitive to demonstrate these variations.

A little difference in the pressure of the oxygen in the blowpipe causes a variation in the temperature of the incandescent lime, and consequently in the quality of the light emitted; for the higher the temperature the richer the light becomes in refrangible rays. At each passage through the glasses, and at each reflection on the mirrors, a small quantity of light is lost; so that the colour of all the reflected images is not exactly the same. In proportion as the number of reflections increases, the colour of the corresponding images approaches the colour emitted in large quantity by the source.

In order to profit fully by the sensitiveness of the apparatus, and to effect the measurements with the utmost precision of which they were capable, it was necessary, in each of the experiments, to estimate the average length of the luminous rays which reached the eye.

Measurements were taken of the rotation of the plane of polarization of these rays while passing through the same column of carbon bisulphide, or of some other body, such as glass, with which the phenomenon was previously studied.

For carbon bisulphide, for instance, the relations of the magnetic rotations to the yellow rays $\mathrm{D}$, and to rays of any wave-length whatever, were known. It sufficed, then, to know the magnetic rotation of the rays studied, compared with the rotation of the yellow light, in order to be able to deduce the approximate value of the wave-length from it. I have already bad orcasion to apply this method in my previous researches*, and subsequently $\dagger$ to verify the accuracy of the results thus obtained.

* Annales de Chimie et de Physique, t. xii. 1877.

+ Comptes Rendus de l'Académie des Sciences, t. $1 \times x \times x v$.

Phil. Mag. S. 5. Vol. 12. No. 77. Dec. 1881. 
In order to measure the rotation of the plane of polarization of light, other methods might be employed, by which the wave-length of the light under measurement would be very accurately ascertained; but, as I have already remarked in the memoir above quoted, these methods do not admit of the same sensibility as the shaded polariscope when the rotations to be measured are very small. In the present researches I propose to determine, at the same time, the magnetic rotations of various gases with luminous rays having the same wavelength, and to compare amongst themselves the magnetic rotatory powers of the same body with luminous rays having different wave-lengths. It has just been shown that the two studies should be pursued side by side.

I made use of the light of incandescent lime seen either directly or through coloured screens, which were :-

1. Rather dark-red glasses, made with cuprous oxide.

2. Light-yellow glasses.

3. A bluish green glass, which intercepted nearly all the red rays, and chiefly allowed rays to pass bordering on group $\mathbf{E}$ in the solar spectrum.

4. A liquid screen containing ammoniacal copper nitrate, which gave passage to a pencil of luminous rays, the most intense part of which had an average wave-length included between the lines $\mathrm{E}$ and $\mathrm{F}$ in the solar spectrum.

These various luminous sources, seen through a column of 0.50 metre of carbon bisulphide, gave the following results :-

The rotation obtained under the same magnetic conditions for the yellow rays $D$ was taken as unity. The divergencies observable in the results relating to the same coloured light arise from the differences in temperature of the source during the various series, and show the importance attaching to the variations in brilliancy of the incandescent lime.

These results correspond to the light received after a single passage of the luminous rays through the apparatus; as is seen, they are rather variable with the luminous intensity. The first series was obtained with a particularly feeble intensity; while the other results, which are more concordant, correspond to very nearly the maximum temperature that I was able to impart to the cylinder of lime, a condition that I always sought to realize in the experiments. In order to fix the wave-length of each of the refiected images more precisely, I operated in the following manner:-The large tube was withdrawn from the interior of the coils, and the glasses unscrewed and placed inside the first coil, into which I caused the full current from the pile to pass, by detaching the other coils from the circuit. By this means the magnetic intensity became very considerable. I then arranged the optical system 
in the same way as for my experiments with the gases. The luminous rays passed through the glasses several times; and their plane of polarization experienced unequal magnetic rotations, which were measured for each image.

Magnetic Rotations of Carbon Bisulphide, with different luminous Sources.

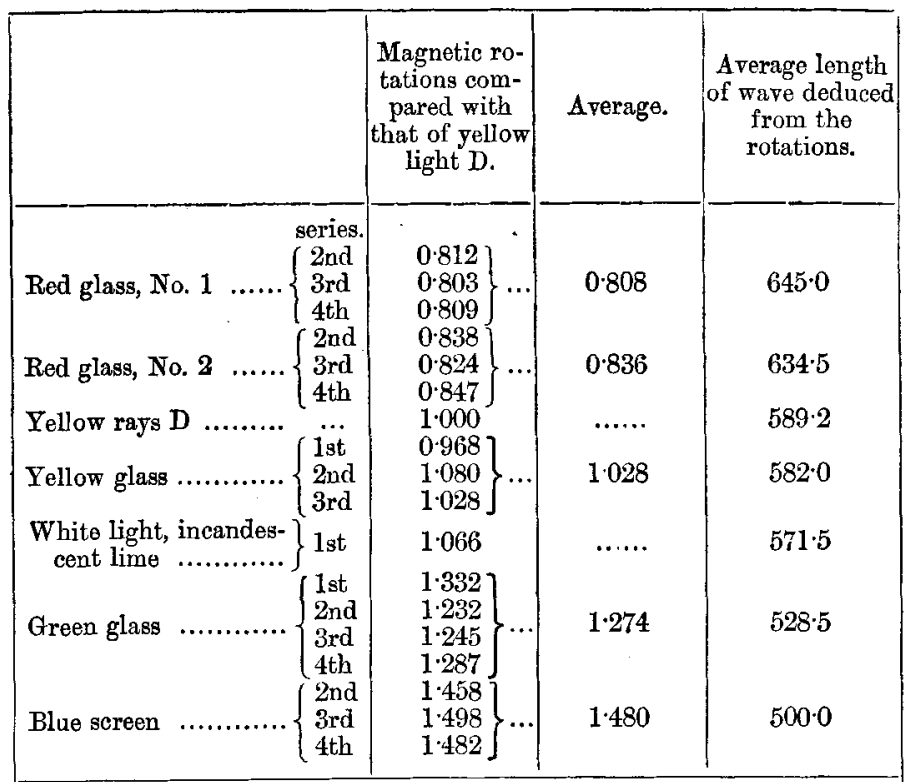

The following Table contains the results obtained. In order to facilitate the comparisons, the numbers observed were reduced to what they would be with the intensity of the electric current which I employed as unity throughout the work; but as they arise from more considerable rotations, their precision is greater. The results are given to the hundredths of a minute; at best the tenths of a minute can be relied on. In this Table I have been obliged to make some corrections, which will be justified later-in particular the action of magnetism on the column of air subjected to the action of the electromagnetic coil, and the influence exerted by the latter on the glass of the nearest mirror.

Finally, as the law of dispersion of the planes of polarization of the various coloured rays is ascertained for the crown glass, the approximate value of the average wavelength of the luminous rays which reach the eye for each image can be reduced from the observed rotations. 


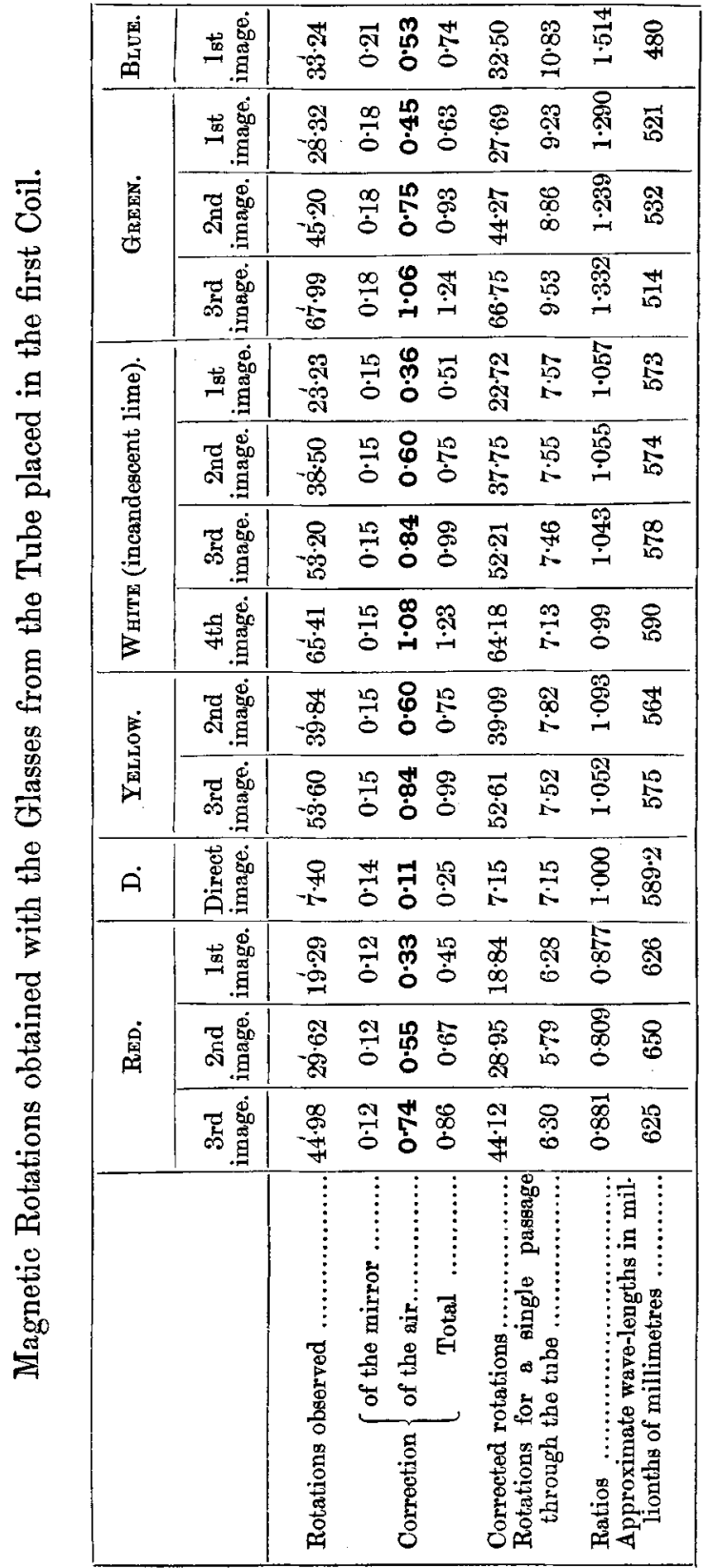


From this it is seen that the wave-lengths deduced from these observations are obviously the same as those with the carbon bisulphide. The composition of the light from the different images reflected varies little when coloured screens are used; but with the light seen directly without screens the influence of coloration from the successive images is very manifest. Thus we find :-

For the direct image . . . . . $\lambda=0.000571$

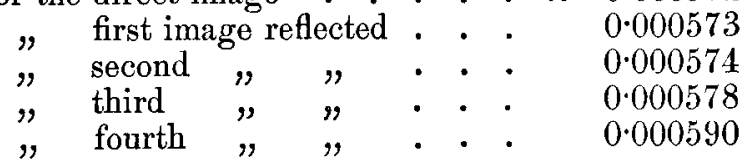

When the number of reflections increases, the refrangibility steadily decreases.

III. Magnetic Rotations caused by the Glasses interposed in the Path of the Luminous Rays. - I have already mentioned that, in consequence of the exigencies of construction, the luminous rays had to pass through rather considerable masses of glass, subjected to an extremely weak electro-magnetic action. Nevertheless the rotatory power of solids is so great, compared with that of gases, that the rotations produced by these masses of glass are of the same order of magnitude as the phenomena to be measured.

A very simple means of determining all the corrections at the same time was to create a vacuum in the tube, and to measure the rotation obtained, under these conditions, for each source of light, then to fill the tube with gas, and make the experiments.

At first I tried to work in this way; but the process presented numerous difficulties-amongst others, exposing the glasses to the risk of fracture. When the tube is empty of air, the glasses support a pressure of about $50 \mathrm{kilog}$; now it is known that under the influence of even a feeble pressure, the rotatory power of bodies diminishes very considerably. The real degree of influence exercised by the glasses on the rotations when the tube is full of gas is therefore not ascertained under these conditions; and the differences are not unimportant. Besides, under the strain which they have to support, the glasses present phenomena of elliptical polarization which completely alter the measurements. In order to avoid these various inconveniences, I adopted the plan of always operating at pressures very nearly equal to atmospheric pressure. Operating by displacement, the tube was filled with the different gases to be studied, several hundreds of litres of gas being passed into it. It is thus possible to ob- 
tain in the tube gases containing only a few hundredths of impurities, of which, however, an account is kept. Under these conditions it is certain that the glasses do not occasion any sensible phenomena of elliptical polarization which can confuse the measurements. For instance, I placed in the immediate vicinity of the polariscope a small tube of sugar and water, giving a rotation of $55^{\prime}$ for yellow light; and on measuring this rotation by means of the fourth reflected image, it was found to have exactly the same rotation, $55^{\prime}$. The rays had then traversed forty surfaces of glass.

It must, however, be remarked that when the tube is very hot the circumference of the glasses becomes unequally heated, and they present slight and momentary indications of strain. The glasses can be set so as to counteract the effects produced ; but it is better to conduct the experiments in such a way as to avoid these perturbations, and to reject the observations which there is reason to believe are affected by this cause of error. In order to ascertain the influence of the glasses, the magnetic rotation through the tube full of air was measured ; then the glasses were unscrewed, and the new rotations obtained measured; the difference between the two gives the action of the glasses. But this difference itself depends upon very small numbers; and it becomes of consequence to try, by special measurements, the value of this correction, since it affects all the other measurements.

The magnetic intensity at the position of the glasses was ascertained either directly or by means of the curve spoken of at page 323. This curve gives the ratio of the magnetic intensities inside the first coil, and at any distance from it. For the glasses whose centre is at about 0.14 metre from the exterior surface of the coils, the ratio of the magnetic intensity experienced has been found to equal 0.067 of that inside the coil.

A heavy piece of glass placed inside the first coil gave for the yellow light a rotation of $106^{\prime} \cdot 10$; and at the place of the glasses in the tube it gave $7^{\prime} \cdot 1$. The ratio of the two rotations is also 0.067 . I adopted this number, and thus, knowing the magnetic rotations of the glasses inside the first coil (p. 399), was able to deduce from them the corrections sought for with the different colours and different images.

To this correction a second but less important one must be added. It has been seen that both before and after the successive reflections, the luminous rays pass through the mirrors themselves. These are made of St.-Gobain glass, and are 7.9 millim. thick. The magnetic intensity to which they are subjected has been found to equal 0.026 of that existing 
inside the first coil; and taking into account the relative thickness of the glasses and mirrors, it is clear that, in order to ascertain the magnetic rotation to which they give rise, the number obtained for the glasses inside the tube must be multiplied by 0.040 .

In this way the following Table, which contains the necessary corrections to be made to the direct measurements, has been drawn up :-

Corrections for the Glasses and the Glass of the Mirrors. Red. 4th image. 3rd image. 2nd image. 1st image.

\begin{tabular}{|c|c|c|c|c|}
\hline \multicolumn{5}{|c|}{ Red. } \\
\hline & 4th image. & 3rd image. & 2nd image. & Ist image \\
\hline$\ldots$ & $\dot{3} \cdot 49$ & $2 \cdot 94$ & $2 \cdot 10$ & $\dot{1} \cdot 26$ \\
\hline irrors.............. & $0 \cdot 25$ & $0 \cdot 25$ & 0.25 & $0 \cdot 2$ \\
\hline & 374 & $3 \cdot 19$ & $2 \cdot 35$ & 1:5 \\
\hline
\end{tabular}

White (incandescent lime); yellow.

4th image (D). 3rd image. 2nd image 1st image.

\begin{tabular}{|c|c|c|c|}
\hline Glasses .............. & $4 \cdot 30$ & 350 & 253 \\
\hline Mirrors ............... & 0.28 & $0 \cdot 29$ & $0 \cdot 30$ \\
\hline & & & \\
\hline
\end{tabular}

Green.

4th image. 3rd image. 2nd image. 1st image.

Glasses

\begin{tabular}{llll}
5.75 & 4.47 & 3.10 & $1 \cdot 85$ \\
0.38 & 0.38 & 0.37 & 0.37 \\
\hline 6.13 & $\frac{4.85}{3.47}$ & &
\end{tabular}

Blue.

4th image. 3rd image. 2nd image. 1st image.

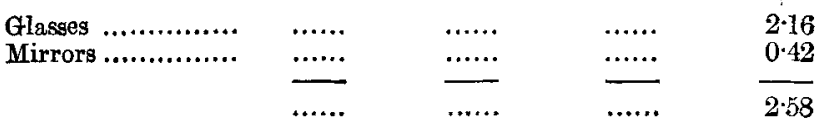

These numbers are obtained from a large number of observations ; although the tenths of a minute may be relied on, the hundredths are given as they resulted from the calculations. In concluding the examination of this question, I may remark that, the rotations to be measured in the gases being very small, all secondary considerations had to be sacrificed to perfection in the arrangement of the optical system, without which perfection the measurements would have been impossible.

IV. Correction for the Temperature.-I stated above that, in 


\section{M. H. Becquerel's Experimental Investigations}

consequence of the passage of the electric current through the coils, the temperature of the tube rose rapidly to $30^{\circ}$ or $40^{\circ} \mathrm{C}$. It was therefore very important to ascertain the average temperature of the gases in each series of experiments.

To do this I measured the temperature of the copper by means of contact-thermometers. Moreover the tube itself acted as a gas-thermometer; it was in constant connexion with a mercurial manometer which, when the atmospheric pressure was ascertained, gave at every moment the pressure of the gas inside the tube. The temperature deduced from observations of the pressure was always the same as that given by the thermometers. The comparison of these temperatures enabled us to discover when there were leakages of gas in the tube.

In order to admit of comparison, the results observed had to be reduced to the same pressure of 760 millim. of mercury and to the same density. The correction relative to the pressure and to the density might amount to 0.10 of the value of the numbers found experimentally.

I have assumed that the magnetic rotatory power of the gases studied between $0^{\circ}$ and $40^{\circ}$ varied proportionately to the density, or in the inverse ratio of the modulus of dilatation $(1+a t)$. The probable existence of a slight variation with the temperature in the molecular rotatory power of the gas has been thus neglected; but it may be remarked that if this variation is of the same order of dimension for gases as for other substances it must escape our measurements; for it is of the order of the errors of observation. The agreement of the results obtained at different temperatures seems to justify this hypothesis. Concerning the numbers given below, it may be stated that they were obtained at a temperature of between $10^{\circ}$ and $40^{\circ}$, and that the different gases were reduced to a uniform pressure and volume by. multiplying the numbers obtained by the factor $\frac{760}{\mathrm{H}}(1+a t), \mathrm{H}$ being the pressure of the gases, $t$ their temperature, and $a$ their coefficient of dilatation.

V. Displacement of the Luminous Point.-The luminous point does not invariably occupy a fixed position. Although t'e blowpipe is fixed to the polariscope, it happens that the luminous point rises or falls on the piece of lime according to the greater or less pressure of the oxygen which feeds the combustion. The lime itself becomes slightly hollow; and on this account the incandescent region is displaced.

These slight displacements of the luminous point cause 
corresponding variations in the plane of polarization of the different images; and if a sudden displacement occurred during the progress of a measurement, the latter would be erroneous. In order to guard against these variations, a large number of consecutive measurements were made by alternating the direction of the electric current in the coils.

During the greater part of the time it was easy to see, by the constancy of the direction of the planes of polarization reflected in one direction or the other, that the luminous point was fixed. From time to time a gradual displacement of the planes of polarization was apparent; but as the deviations in one direction or the other were measured alternately, this cause of error could be eliminated by taking the average of the deviations in one direction and the average of the deviations in the other. All the numbers obtained were examined with great care from this point of view, and the averages calculated in two ways:- the first, by taking the averages of the double rotations directly observed; the second, by deducing the rotation from the difference between the average positions of the planes of polarization deflected in one direction or the other.

When the two calculations did not give exactly the same result, the average of the two numbers was taken. The difference, however, did not generally amount to more than a few tenths of a minute of arc.

Finally, I may add that all the phenomena which might be due to dilatation, even of the copper tube, must be considered as introducing no appreciable perturbation into the measurements.

\section{Accuracy of the Measurements.}

The magnetic rotations obtained for the gases are sometimes so feeble that it is very important to take the most exact account possible of the degree of accuracy of the observations. As will be seen, this determination presents great difficulties; and I shall confine myself to indicating the superior limits of the errors to be feared.

The causes which may vitiate the measurements are the following :-

1st. The greater or less precision in the determination of the position of the planes of polarization, in consequence of the imperfection with which the eye appreciates the equality of tint in the two halves of the image from the polariscope.

2nd. The precision with which the electromagnetic intensity is measured.

3rd. The uncertainty as to the true wave-length of the light studied. 
4th. The greater or less accuracy in the measurement of the temperature and pressure of the gases.

5 th. The accidental displacement of the luminous point.

The influence of the last four causes of error is very slight in comparison with the first. In determining the maximum value of the latter, let us consider the maximum value to which the errors in our measurements might attain. Let $R$ be the magnetic rotation for a given gas, submitted to the action of an electric current of the intensity I, and $A$ the wave-length of the luminous rays to which the observations are being directed, let $\rho$ be the rotation which is to be measured, $i$ and $\lambda$ the wave-length of the light studied. It will be shown afterwards that we can express

$$
\frac{\mathrm{R}}{\mathrm{A}^{2}}=\frac{\rho}{\lambda^{2}} \frac{\mathrm{I}}{i} \frac{760}{\mathrm{H}}(1+a t) .
$$

By taking the logarithms of the two numbers and differentiating, we have

$$
\frac{d \mathrm{R}}{\mathrm{R}}=\frac{d \rho}{\rho}-\frac{2 d \lambda}{\lambda}-\frac{d i}{i}-\frac{d \mathrm{H}}{\mathrm{H}}+\frac{a d t}{1+a t} .
$$

Each of the terms of the second member represents the relative error due to the variation of each element, and may be positive or negative. It is clear that the most unfavourable case for the measurements will be that where the terms have the same sign and are additive. 0.001 .

Now it has been seen above (p. 395) that $\frac{d i}{i}$ cannot exceed

The possible variation of $\lambda$ may be deduced from experiments made with carbon bisulphide (p. 398). It is easily seen that the variations in brilliancy of the incandescent lime through the same coloured screen do not give for the expression $\frac{2 d \lambda}{\lambda}$ greater values than $0.05 ; \frac{d \mathrm{H}}{\mathrm{H}}$ does not amount to 0.002 ; and an error of $1^{\circ}$ must be made in the temperature of the gases in order that the expression $\frac{a d t}{1+a t}$ shall be $0 \cdot 003$.

There remains, then, the error $\frac{d \rho}{\rho}$. With a shaded apparatus the position of equality of tint is easily determined to nearly $1^{\prime}$. As the rotations sought are deduced from the difference between the two measurements, the maximum error cannot exceed $2^{\prime}$.

Let us admit this limited value $d \rho=2^{\prime}$, and let us calculate the relative error for two gases-air, which produces the smallest rotations, and olefiant gas, which produces the 
largest :

$$
\begin{aligned}
& \text { For air. . . } \rho=6^{\prime} \cdot 4 \frac{d \rho}{\rho}=0.3, \frac{d \mathrm{R}}{\mathrm{R}}=0.35, \\
& \text { For olefiant gas } \rho=40^{\prime} \cdot 0 \frac{d \rho}{\rho}=0.05, \frac{d \mathrm{R}}{\mathrm{R}}=0.10 .^{\prime}
\end{aligned}
$$

Strictly speaking, then, in a single determination it would be possible to commit an error which would vary between the third and the tenth of the rotation, according to magnitude of the rotation.

These numbers are far from giving the precision which may be attained by increasing the observations. For example, we made on the two gases that we have just cited about a hundred and fifty measurements, which mutually tested each other, and enabled us to see which observations were too inexact and ought to be rejected.

Not being able to determine separately the value of the most important causes of error, we attempted to make the precision of each series evident by means of the greater or less agreement in the measurements. Suppose that the average of the numbers for a series of observations is the true value of the rotation sought; the individual measurements can then be compared with this average, and the positive or negative doviations calculated in each case. Giving the same sign to all of them, and taking the average, a number will result that we will call the "average deviation," and which will give an idea of the precision of each of the measurements in a series. In this calculation all the observations were taken into account, even those which presented exceptionally large deviations due to accidental causes. In the following Tables we have put in opposite columns the numbers adopted, and the value of the average deviation calculated in this way for each series; but it must be observed that this deviation is not the error which is probably to be feared. As might be anticipated, it is much smaller, as, indeed, the agreement of the results deduced from different series demonstrates. The average deviations are only superior limits of the errors.

If the only cause of error were that which relates to the optical measurements, the different series ought to give the rotations sought with a precision proportionately greater as the image reflected is of a higher order; for the same error would enter into a multiple of unknown quantity, and the application of the method of least squares would be clearly indicated; but certain perturbations, such as a variation in the wave-length of the light studied, enter into the value of 
even the unknown rotation. It was therefore necessary to compare each of the rotations with the average wave-length which corresponded to it.

It has been stated that the results obtained with differentcoloured rays are very nearly in the inverse ratio of the square of the wave-lengths; and the departures from this simple law are of the order of errors of observation. This observation, then, enabled us to employ, for the determination of the magnetic rotation corresponding to luminous rays of a given wave-length, for example the yellow rays D, all the observations relative to the same gas, which in the case of air and olefiant gas amounted to a hundred and fifty.

Now the average of a hundred observations made with the greatest care possible may be.considered as ten times more exact than a single isolated measurement; it is clear, then, that for the numbers in question, an accuracy of $\frac{1}{10}$ of the minute of arc may be relied on.

It will be shown (p. 428) that the numbers deduced, as has just been said, from observations relative to various colours do not differ amongst themselves by more than $\frac{1}{70}$ for air and $\frac{1}{360}$ for olefiant gas.

In the Tables that follow, the numbers are expressed in minutes of arc; and although the first decimal figure cannot always be relied on, I have given the results to two decimal figures, as they resulted from the calculation of the averages.

\section{Experimental Determinations.}

It has just been shown what was the relative importance of the different corrections which affect the direct observations. Among them there is one that applies to all the other corrections; this is the variation in the electromagnetic intensity.

It was ascertained that this varied only within restricted limits; and in order to render the numbers comparable, we made this correction first of all. The tables which follow contain only numbers thus corrected. The values of the other corrections are given in the tables themselves, in order that their relative importance may be justly estimated; for they allow of the same causes of error as the observations themselves. We now proceed to examine successively the results obtained with different gases.

Atmospheric Air.- The observations relative to atmospheric air were numerous, first, because the magnetic rotations of this body constituted an important physical datum, and, secondly, because it was possible to effect the determinations without interposing the tube-glasses in the path of the light, and thus to verify the numbers adopted for the magnetic 
rotations due to the passage of the luminous rays through these glasses. Besides the determinations which follow, a great number of others were made before the apparatus had received its definite and final form. However, the average of the results found previously is identical with that which is deduced from the following numbers:-

Atmospheric Air.

\begin{tabular}{|c|c|c|c|c|c|c|}
\hline Series. & $\mid \begin{array}{c}\text { Average } \\
\text { tempera- } \\
\text { ture, } t\end{array}$ & $\begin{array}{c}\text { Average } \\
\text { pressure, } \\
\text { H. }\end{array}$ & $\begin{array}{l}\text { Correction, } \\
\frac{(1+a t) 760}{\mathrm{H}} .\end{array}$ & $\begin{array}{c}\text { Numbers } \\
\text { observed and } \\
\text { corrections. }\end{array}$ & $\begin{array}{c}\text { Corrected } \\
\text { magnetic } \\
\text { rotations. }\end{array}$ & $\begin{array}{l}\text { Mean } \\
\text { devia- } \\
\text { tions. }\end{array}$ \\
\hline \multicolumn{7}{|c|}{$\begin{array}{l}\text { White LiGHT (incandescent lime). - - 4th image (9 passages). } \\
\text { rements without the tube-glassee. (Former arrangement of the apparatus.) }\end{array}$} \\
\hline May $13,1879$. & $30 \cdot 7$ & $\underset{764 \cdot 0}{\operatorname{millim}}$ & $1 \cdot 100$ & $6 \cdot 17$ & 678 & $1 \cdot 1$ \\
\hline \multicolumn{7}{|c|}{ Final arrangement. } \\
\hline \multirow[t]{2}{*}{$\operatorname{Jan} .16,1880$} & $10 \cdot 0$ & $763 \cdot 2$ & 1.033 & $\begin{array}{r}6.56 \\
\text { Mirrors } 0 \cdot 28\end{array}$ & \multirow{2}{*}{$6 \cdot 48$} & \multirow{2}{*}{$1 \cdot 8$} \\
\hline & & & & Diff. $\overline{6.28}$ & & \\
\hline \multirow[t]{2}{*}{ March 19, 1880} & $160^{\circ}$ & $768 \cdot 0$ & $1 \cdot 048$ & $\begin{array}{r}6 \cdot 44 \\
\text { Mirrors } 0 \cdot 28\end{array}$ & \multirow{2}{*}{$6 \cdot 45$} & \multirow{2}{*}{$1 \cdot 0$} \\
\hline & & & & Diff. $\quad \overline{6 \cdot 16}$ & & \\
\hline \multicolumn{7}{|c|}{ 2nd. Measurements with the tube-glasses. } \\
\hline Jan. $19,1880$. & $16 \cdot 5$ & $762 \cdot 8$ & $1 \cdot 056$ & $\begin{array}{rr} & 10 \cdot 74 \\
\text { Corr. } & 4.58\end{array}$ & \multirow[t]{2}{*}{$6 \cdot 50$} & \multirow{2}{*}{$1 \cdot 0$} \\
\hline & & & & Diff. $\quad \overline{6 \cdot 16}$ & & \\
\hline \multirow[t]{2}{*}{ March 11, 1880. } & 140 & $801 \cdot 3$ & 1.032 & Corr. $\begin{array}{r}10 \cdot 92 \\
4.58\end{array}$ & \multirow[t]{2}{*}{6.54} & \multirow{2}{*}{$1 \cdot 6$} \\
\hline & & & & Diff. & & \\
\hline \multirow{3}{*}{ March 6, 1880} & \multicolumn{4}{|c|}{ 3rd image ( 7 passages). } & \multirow{3}{*}{$5 \cdot 14$} & \multirow{3}{*}{$1 \cdot 1$} \\
\hline & $21 \cdot 0$ & $791 \cdot 8$ & $1 \cdot 033$ & $\begin{array}{ll}8 \cdot 77 \\
\text { Corr. } \quad 3 \cdot 79\end{array}$ & & \\
\hline & & & & Diff. & & \\
\hline \multicolumn{7}{|c|}{$\begin{array}{l}\text { YkLLOW LIGHT (yellow glass).-4th image ( } 9 \text { passages). } \\
\text { 1st. Measurements without the glasses. }\end{array}$} \\
\hline \multirow[t]{4}{*}{ March 19,1880} & $20 \cdot 7$ & $767 \cdot 9$ & $1 \cdot 064$ & $\begin{array}{r}6 \cdot 15 \\
\text { Mirrors } 0.28\end{array}$ & \multirow{2}{*}{$6 \cdot 18$} & \multirow{2}{*}{$0 \cdot 8$} \\
\hline & & & & Diff. $\quad 5.87$ & & \\
\hline & $35 \cdot 0$ & 7663 & $1 \cdot 119$ & $\begin{array}{r}5.05 \\
\text { Mirrors } 0.28\end{array}$ & & \\
\hline & & & & Diff. $\quad \overline{4 \cdot 77}$ & 534 & 0.4 \\
\hline
\end{tabular}


Table (continued).

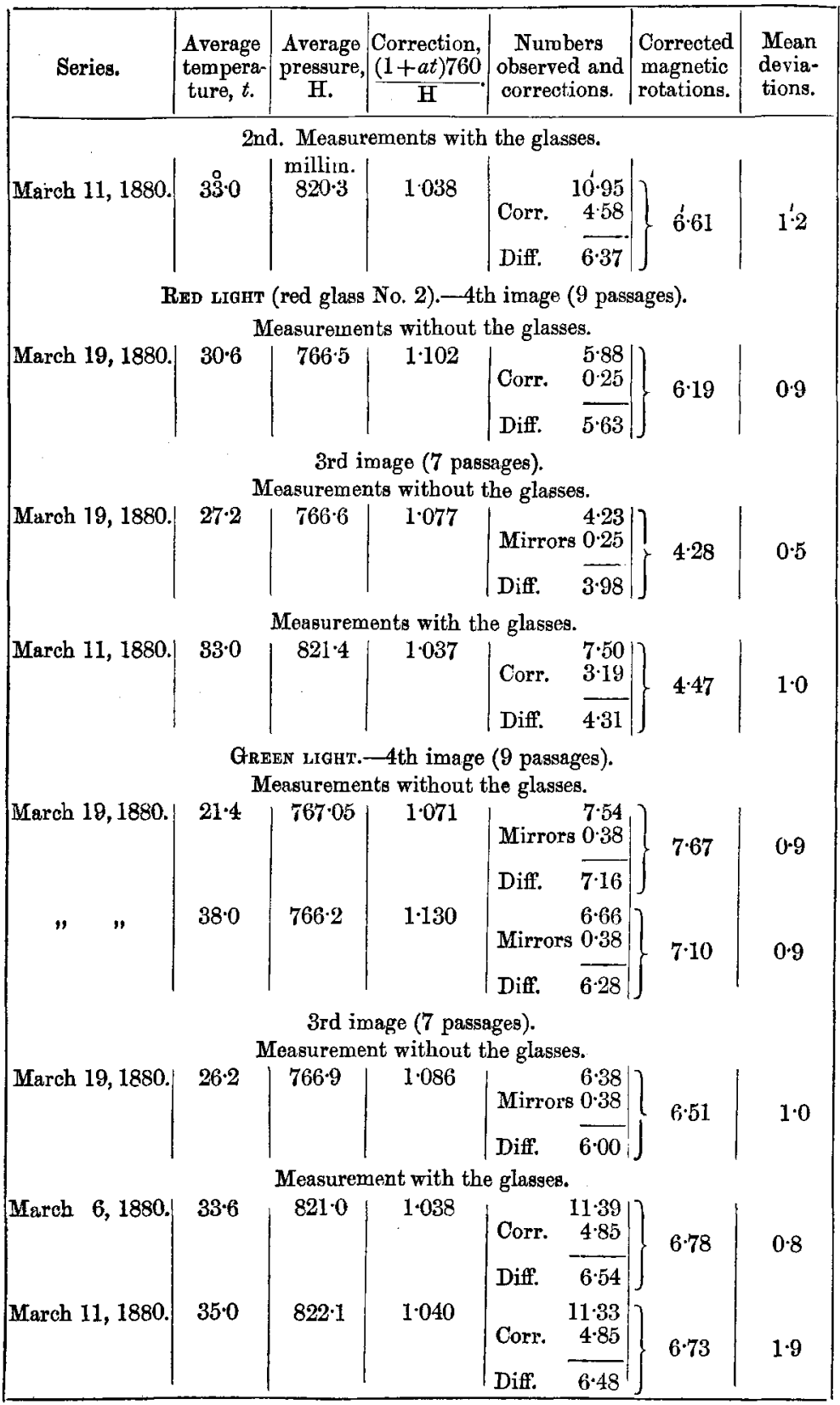


Table (continued).

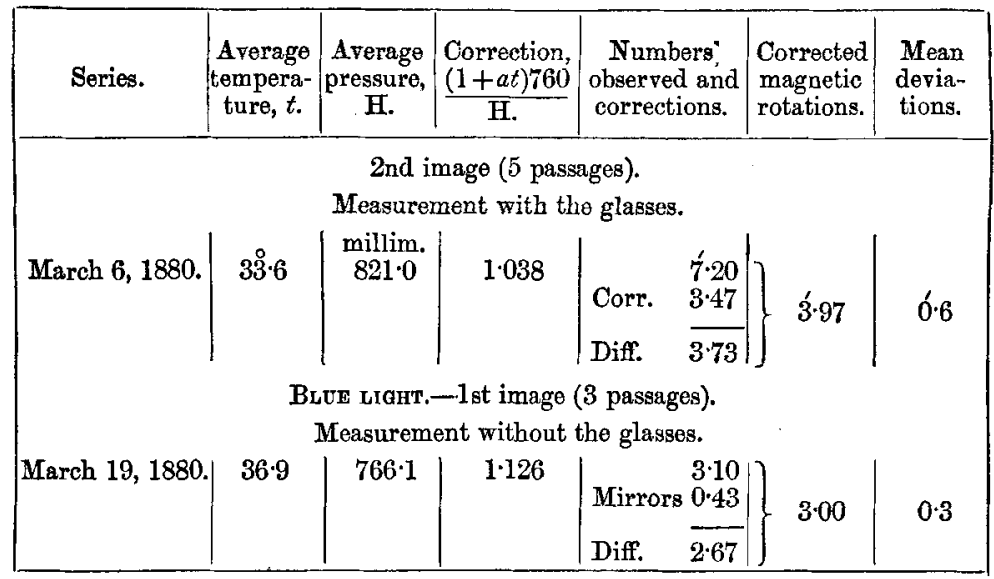

Oxygen.-The oxygen was prepared by mixing chlorate of potash with a little binoxide of manganese. The greatest care was taken to purify the gas from the chlorine always contained in it: this was done by passing it several times very slowly through a solution of potash, and then over pumice moistened with a concentrated solution of potash. The gas was dried by passing over fragments of pumice moistened with sulphuric acid and then over calcium chloride.

In this way several hundreds of litres of gas were prepared in bags which had been used for some time; and the oxygen was slowly introduced into the tube by causing it to pass once more through the series of purifying and drying tubes. The oxygen displaced the air, so that eventually the tube was filled with a mixture containing only a few hundredths of impurities. Several methods were employed for analyzing the oxygen, hydrochloric acid and copper being principally used. In this way we obtained for the mixture studied as below:-

On the 27 th of February, 1880, out of 134 vol. of gas, 3.5 rol. of residuum, which we may admit to be nitrogen (say 0.9739 of oxygen and 0.0261 of nitrogen). After having made the determinations with this gas, a fresh analysis, made on the 3rd of March, yielded out of 121 vol., a residue of 3.4 vol. (say 0.972 of oxygen and 0.028 of nitrogen).

It is to be noted that, between the two series of experiments, a fresh quantity of gas was passed into the tube. It may be admitted that we had an average of 0.973 of oxygen and 0.027 of nitrogen. The following numbers were obtained:- 
Oxygen, 0.9730+0.027 Nitrogen.

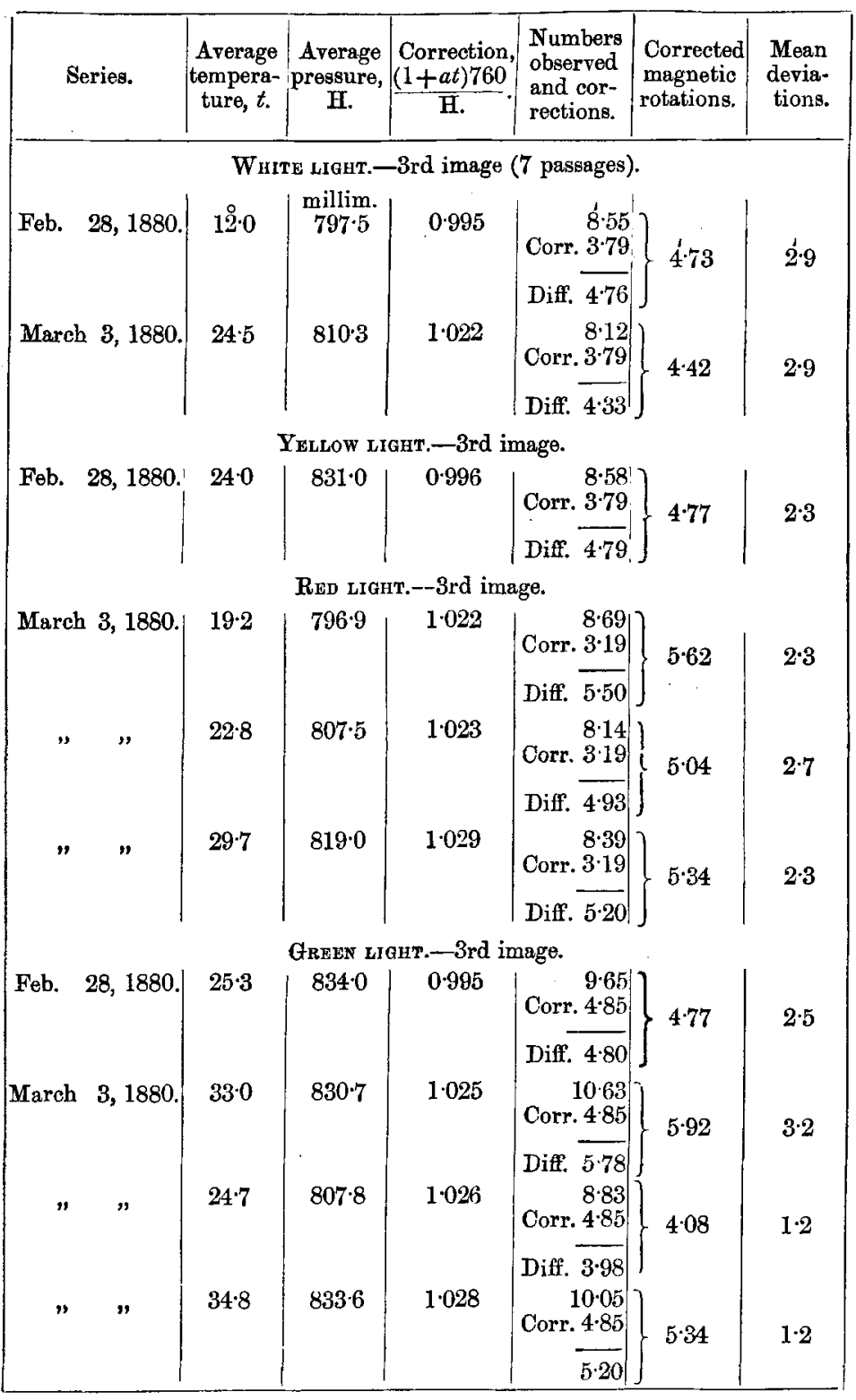

The average of all the observations made March 3rd on the 
third image, by alternating the measurements relative to the red rays and to the green rays, produced:-

\begin{tabular}{|c|c|c|}
\hline \multirow[b]{2}{*}{ Rotation ......... } & \multicolumn{2}{|c|}{ Third image. } \\
\hline & $\begin{array}{l}\text { Red. } \\
8.55\end{array}$ & $\begin{array}{r}\text { Green } \\
9 \cdot 61\end{array}$ \\
\hline Correction.......... & $3 \cdot 19$ & $4 \cdot 85$ \\
\hline Difference... & $5 \cdot 34$ & $4 \cdot 76$ \\
\hline
\end{tabular}

These numbers will be discussed later. From the beginning of the experiments the series relative to the oxygen presented anomalies upon which I shall dwell presently. I also made a further series of observations with this gas, some at the beginning of the experiments in 1879 , others at the end of January 1880 , and, finally, the determinations which I have just recorded.

The latter correspond to a purer gaseous mixture than the previous series. I judged it useless to reproduce the numbers relative to the former series; they, however, completely confirmed those just given.

Nitrogen.-The nitrogen was prepared by passing air very slowly through two tubes, 0.50 metre long, filled with copper turnings, heated to a red heat in porcelain tubes. The gas was received in a large gasometer, and afterwards made to pass, after drying, into the tube previously full of air.

The gaseous mixture was analyzed by means of cold phosphorus; and out of $150 \mathrm{vol}$. of gas a residuum of 136.5 was produced. The following are the results obtained:-

Nitrogen, $0.91+0.090$ Oxygen.

\begin{tabular}{|c|c|c|c|c|c|c|}
\hline Series. & $\begin{array}{l}\text { Average } \\
\text { tempera- } \\
\text { ture, } t \text {. }\end{array}$ & $\begin{array}{c}\text { Average } \\
\text { pressure, } \\
\mathbf{H} .\end{array}$ & $\begin{array}{l}\text { Correction, } \\
\frac{(1+a t) 760}{\mathrm{H}}\end{array}$ & $\begin{array}{l}\text { Numbers } \\
\text { observed } \\
\text { and cor- } \\
\text { rections. }\end{array}$ & $\begin{array}{l}\text { Corrected } \\
\text { magnetic } \\
\text { rotations. }\end{array}$ & $\begin{array}{c}\text { Mean } \\
\text { devia- } \\
\text { tions. }\end{array}$ \\
\hline \multicolumn{7}{|c|}{ White LiGHT.—4th image (9 passages). } \\
\hline Jan. $16,1880$. & 200 & $\underset{762 \cdot 6}{\operatorname{millim}}$ & 1.069 & $\begin{array}{r}11 \cdot 00 \\
\text { Corr. } \frac{4 \cdot 58}{1.42} \\
\text { Diff. } 6.42\end{array}$ & 6. & 26 \\
\hline
\end{tabular}

The numbers obtained for air and oxygen ought to enable us to find the number relative to the nitrogen. By correcting the number above obtained by the 0.09 vol. of oxygen which it contains, we obtain for the pure nitrogen the number 6.95 .

Let us now calculate the rotation of the nitrogen by means of those of the air and oxygen. Let us take, for example, the Phil. Mag. S. 5. Vol. 12. No. 77. Dec. 1881. 2 I 
numbers relating to the third white image. We have:-

whence

$$
\begin{aligned}
& \text { Air, } 0.2080+0.792 \mathrm{~N} . . . \ldots . . . \quad 5 \cdot 14 \\
& 0.208 \text { oxygen.............. } 0.95
\end{aligned}
$$

and

$$
\begin{array}{lll}
0.792 \mathrm{~N} \ldots \ldots . \ldots \ldots \ldots \ldots \ldots . . & 4 \cdot 19 \\
\mathrm{~N} \text { (3rd image) } & . . . \ldots \ldots \ldots . . & 5 \cdot 29
\end{array}
$$$$
\mathrm{N} \text { (4th image) ........... } 6 \cdot 80
$$

This number agrees sufficiently well with the direct determinations ; for we cannot count on a greater precision.

Nitrogen Monoxide.-Nitrogen monoxide was prepared by the decomposition of ammonium nitrate, and collected over water saturated with this gas. It was subsequently passed into the tube, which was then full of a mixture of 0.70 of oxygen and 0.30 of nitrogen.

The gas was analyzed by absorbing it by water; in this analysis account must be taken of the air dissolved in the water, and which is evolved on the solution of the gas which is more soluble. In this way we obtained for the mixture:-

$$
\begin{array}{lll}
\text { Nitrogen monoxide ............ } & 0 \cdot 691 \\
\text { Nitrogen ........................ } & 0 \cdot 219 \\
\text { Oxygen........................ } & 0 \cdot 090
\end{array}
$$

Cold phosphorus was employed for the analysis of the mixture not absorbed by the water.

The gas, as we see, was very impure; and this disadvantage

\begin{tabular}{|c|c|c|c|c|c|c|}
\hline Series. & $\begin{array}{l}\text { Average } \\
\text { tempera- } \\
\text { ture, } t .\end{array}$ & $\begin{array}{c}\text { Average } \\
\text { pressure, } \\
\mathbf{H} .\end{array}$ & $\mid \begin{array}{l}\text { Correction, } \\
\frac{(1+a t) 760}{\mathbf{H}}\end{array}$ & $\begin{array}{l}\text { Numbers } \\
\text { observed } \\
\text { and cor- } \\
\text { rections. }\end{array}$ & $\begin{array}{c}\text { Corrected } \\
\text { magnetic } \\
\text { rotations. }\end{array}$ & $\begin{array}{l}\text { Mean } \\
\text { devia- } \\
\text { tions. }\end{array}$ \\
\hline \multicolumn{7}{|c|}{ WhIte LiGht, -4th image. } \\
\hline Jan. 30, 1880 & $2 \stackrel{\circ}{2} 0$ & $\underset{772 \cdot 0}{\operatorname{millim}}$ & $1 \cdot 067$ & $\begin{array}{r}17 \cdot 10 \\
\text { Corr. } 4 \cdot 58 \\
\text { Diff. } \overline{12 \cdot 52}\end{array}$ & $13 \cdot 36$ & $1 \cdot 7$ \\
\hline \multicolumn{7}{|c|}{ GreEN LIGHT.-4th image. } \\
\hline Jan. 30, 1880. & $26 \cdot 9$ & $774 \cdot 0$ & $1 \cdot 067$ & $\begin{array}{r}21 \cdot 12 \\
\text { Oorr. } 6 \cdot 13 \\
\text { Diff. 14.99 }\end{array}$ & 15.99 & $4 \cdot 2$ \\
\hline
\end{tabular}
must be attributed to the air dissolved in the water of the gasometer, and which was evolved, either by a partial vacuum being produced in the upper part of the gasometer, or by the solution of nitrogen monoxide in the water.

The following numbers were obtained for the preceding mixture :- 
The rotations which would be given by protoxide in a pure state can be deduced from the preceding numbers; in fact, we have for the fourth image (whito light):-

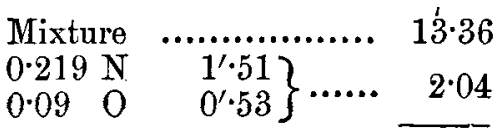

whence

$$
0.691 \mathrm{~N}_{2} \mathrm{O}
$$

From this is deduced:-

$$
\mathrm{N}_{2} \mathrm{O} \text { (4th white image)... } 16^{\prime} \cdot 38
$$

The same calculation can be made for the green light; indeed we have for the 4th image (green light):-

\section{whence}

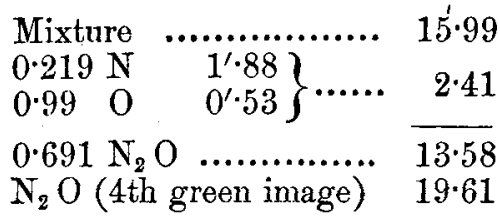

Carbonic Acid.-The carbon dioxide was prepared by the action of hydrochloric acid on white marble. A current of this gas, previously dried, was passed for a very long time into the tube, which contained at the time the mixture of nitrogen monoxide, oxygen, and nitrogen above mentioned.

This gas was analyzed by absorbing it by water; and out of $154 \mathrm{vol}$. of gas I found a residuum of 3 vol. (say 0.0195 of impurities and 0.9805 of carbonic acid). This gas may be considered pure; and the numbers obtained can only admit an inappreciable correction; for it happens that the carbonic acid has very nearly the same magnetic rotatory power as the mixture which constitutes the 0.019 of impurities. The results

\begin{tabular}{|c|c|c|c|c|c|c|}
\hline Series. & $\begin{array}{c}\text { Average } \\
\text { tempera- } \\
\text { ture, } t \text {. }\end{array}$ & $\begin{array}{c}\text { Average } \\
\text { pressure, } \\
\mathbf{H} .\end{array}$ & $\begin{array}{l}\text { Correction, } \\
\frac{(1+a t) 760}{\mathbf{H}}\end{array}$ & $\begin{array}{l}\text { Numbers } \\
\text { observed } \\
\text { and cor- } \\
\text { rections. }\end{array}$ & $\begin{array}{c}\text { Corrected } \\
\text { magnetic } \\
\text { rotations. }\end{array}$ & $\begin{array}{l}\text { Mean } \\
\text { devia- } \\
\text { tions. }\end{array}$ \\
\hline \multicolumn{7}{|c|}{ White Light.-4th image. } \\
\hline Feb. 6, 1880. & $17 \cdot 5$ & $\underset{808 \cdot 4}{\operatorname{millim}}$ & $1 \cdot 000$ & $\begin{array}{r}16 \cdot 90 \\
\text { Corr. } 4 \cdot 58 \\
\text { Diff. } 12 \cdot 32\end{array}$ & $12 \cdot 32$ & $2 \cdot 7$ \\
\hline \multicolumn{7}{|c|}{ GREEN LIGHT.-4th image. } \\
\hline Feb. 6, 1880 & $20 \cdot 0$ & $815 \cdot 8$ & $1 \cdot 000$ & $\begin{array}{r}21.50 \\
\text { Corr. } 6.13 \\
\text { Diff. } 15.37 \\
\end{array}$ & $15 \cdot 37$ & $2 \cdot 6$ \\
\hline
\end{tabular}
obtained are given in the following table:- 
416 M. H. Becquerel's Experimental Investigations

Sulphurous Acid.-This gas was prepared by the volatilization of liquefied anhydrous sulphurous acid, for which I am indebted to the kindness of M. Raoul Pictet. The gas thus obtained was perfectly dry. It was introduced into the tube which contained dry air.

In order to analyze this gas, it was, on issuing from the tube, received in small glass tubes which were hermetically closed; subsequently one of the ends of these tubes was broken over boiled water containing potash, and the gas was analyzed by absorption. By exactly gauging the volume of the small tube as well as the volume of the gaseous residuum not absorbed by the potash, it was ascertained that the mixture enclosed in the tube contained 0.984 of sulphurous acid and 0.016 of air. With this gas the following numbers were obtained :-

Sulphurous acid, $0.984 \mathrm{SO}^{2}+0 \cdot 016 \mathrm{Air}$.

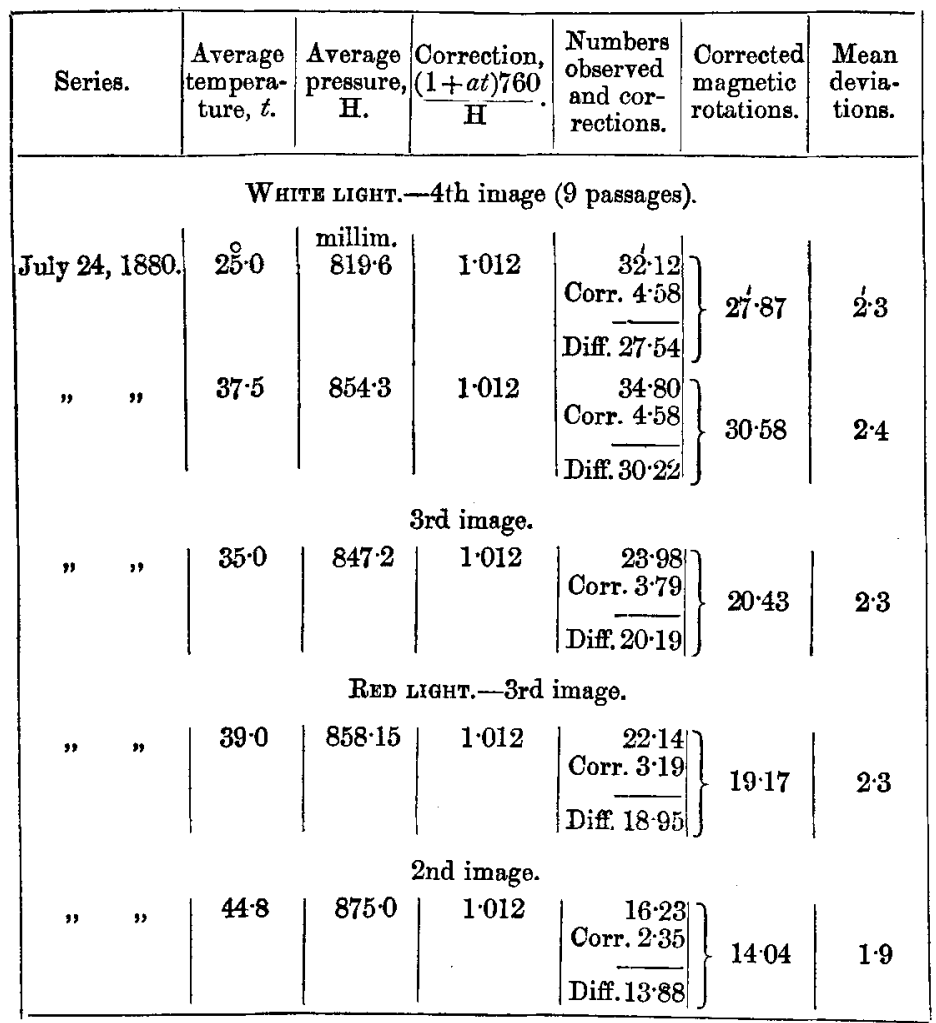


Table (continued).

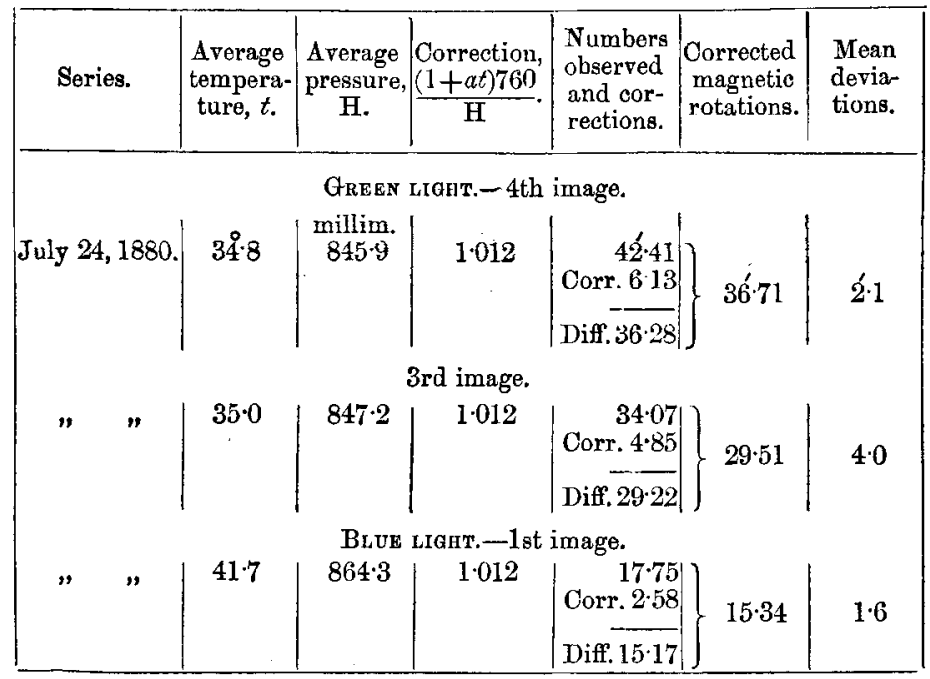

By taking into account the 0.016 of air in the gaseous mixture, we may calculate by means of the preceding numbers the rotations that we should have with the gas absolutely pure. We should find thus:-

$$
\begin{aligned}
& \text { 4th white image ........ } 29.90 \\
& \text { 4th green image ......... } 37 \cdot 19
\end{aligned}
$$

Olefiant Gas.-A preliminary series of experiments performed upon a mixture of 0.72 of olefiant gas and 0.27 of carbonic acid, proved that this body was endowed with a relatively great magnetic rotatory power; and we took extreme precautions to obtain in the tube gas in its purest possible condition. More than 300 litres of olefiant gas were passed into the tube. This gas was prepared by the action of sul. phuric acid on alcohol, purified from ether by passing through sulphuric acid, and from the sulphurous acid (which was produced in rather large quantities) by passing through potash. By remaining in the gasometer the gas became completely freed from the small quantity of sulphurous acid which might remain; but it was always mixed with a little air.

'l'he mixture was analyzed by passing a known volume of the gas into a small graduated tube and then introducing chlorine, bubble by bubble, so as to form ethylene chloride; the excess of the chlorine was subsequently absorbed by potash. 
In this analysis account must be taken of a small quantity of air that may be introduced by the chlorine, as well as of the air which is evolved from the liquid by absorbing the chlorine through the potash.

From careful experiments I found, before commencing the first series recorded below, that the gas contained 0.044 of air. In the interval between the first and second series, the tube being very hot, a little gas was lost by the closing of the glasses. At.the end of the second series two closely agreeing analyses gave 0.061 of impurities. It may be assumed that we had on an average a mixture containing 0.95 of olefiant gas and 0.05 of air.

A great number of measurements for the different images and colours were made with this body, because the rotations, relatively great, were to serve as verification of our experimental method.

A direct determination made with the yellow light of soda gave, for the first image, a number very close to those which would be deduced from the rotation obtained with the fourth white image. There is no use in giving this number, because, on account of the feeble intensity of the light, it was not possible to ensure the same precision as in the case of the other measurements.

We subjoin the results of our measurements with olefiant gas.

Olefiant Gas, $0.95 \mathrm{C}_{2} \mathrm{H}_{4}+0.05$ Air.

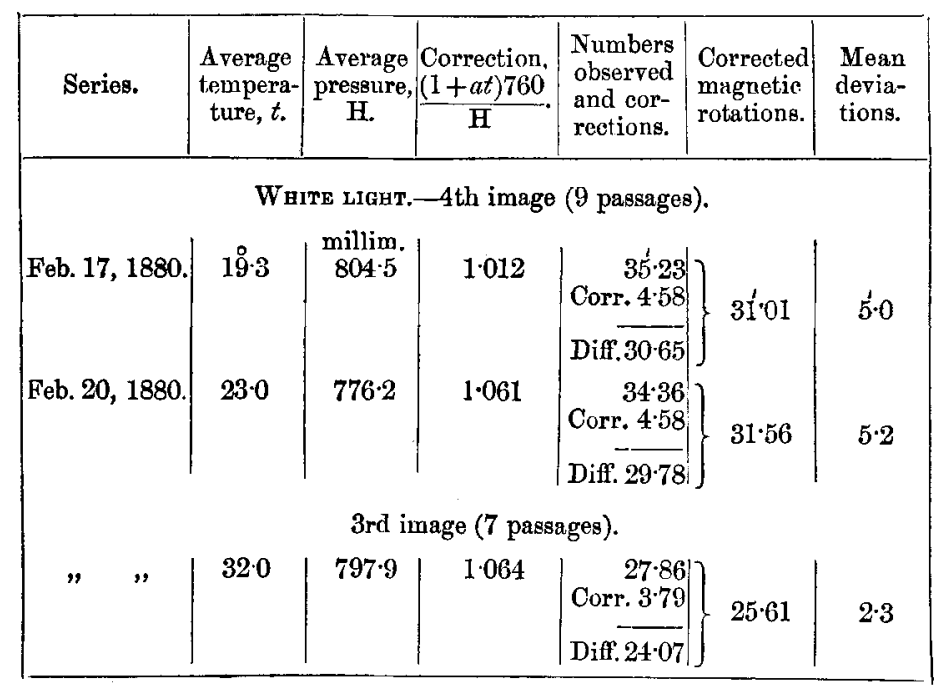


Table (continued).

\begin{tabular}{|c|c|c|c|c|c|c|}
\hline Series. & $\begin{array}{c}\text { Average } \\
\text { tempera- } \\
\text { ture, } t .\end{array}$ & $\begin{array}{c}\text { Average } \\
\text { pressure, } \\
\text { H. }\end{array}$ & $\left\{\begin{array}{c}\text { Correction, } \\
\frac{(1+a t) 760}{\mathbf{H}}\end{array}\right.$ & $\begin{array}{l}\text { Numbers } \\
\text { observed } \\
\text { and cor- } \\
\text { rections. }\end{array}$ & $\begin{array}{l}\text { Corrected } \\
\text { magnetic } \\
\text { rotations. }\end{array}$ & $\begin{array}{l}\text { Mean } \\
\text { devia- } \\
\text { tions. }\end{array}$ \\
\hline Feb. 20, 1880 . & $3 \stackrel{2}{2} \cdot 0$ & $\begin{array}{l}\text { 2nd in } \\
\text { millim. } \\
797 \cdot 9\end{array}$ & $\begin{array}{l}\text { mage ( } 7 \text { pass } \\
\begin{array}{r}1.064 \\
\end{array}\end{array}$ & $\begin{array}{l}\text { ages). } \\
20 \cdot 49 \\
\text { Corr. } 2 \cdot 86 \\
\text { Diff. } 17 \cdot 63\end{array} \mid$ & $18 \cdot 82$ & 0.9 \\
\hline$" \quad "$ & $35 \cdot 6$ & $\begin{array}{l}\text { 1st im } \\
805 \cdot 7\end{array}$ & $\begin{array}{l}\text { age }(3 \text { passe } \\
1.065\end{array}$ & $\mid \begin{array}{l}12 \cdot 24 \\
\text { Corr. } 1 \cdot 82 \\
\text { Diff. } \overline{10 \cdot 42}\end{array}$ & $11 \cdot 10$ & $0 \cdot 9$ \\
\hline$"$ & $\begin{array}{c}\text { YELL }_{29 \cdot 7} \\
29\end{array}$ & $\begin{array}{l}783 \cdot 2 \\
\end{array}$ & $\begin{array}{l}\text { (yellow glas } \\
1.075\end{array}$ & $\left|\begin{array}{r}\text { s). }-4 \text { th ima } \\
35 \cdot 23 \\
\text { Corr. } 4.58 \\
-\square \\
30 \cdot 65\end{array}\right|$ & $\left\{\begin{array}{l}\text { age. } \\
32 \cdot 85\end{array}\right.$ & $5 \cdot 3$ \\
\hline \multicolumn{7}{|c|}{\begin{tabular}{c|c}
3 rd image. \\
787.6 & 1.078
\end{tabular}} \\
\hline$"$ & $\begin{array}{l}\text { YELL } \\
34: 0\end{array}$ & $\begin{array}{l}\text { OW LIGHT } \\
787.8\end{array}$ & $\begin{array}{l}\text { (yellow glas } \\
\quad 1.080\end{array}$ & $\left|\begin{array}{r}18.53 \\
\text { Corr. } 2880 \\
\text { Diff. } 15 \cdot 73\end{array}\right|$ & $\begin{array}{l}\text { age. } \\
16.99\end{array}$ & $1 \cdot 7$ \\
\hline " & $36 \cdot 0$ & $795 \cdot 2$ & $\begin{array}{l}\text { 1st image. } \\
1.082\end{array}$ & $\left|\begin{array}{r}10 \cdot 74 \\
\text { Corr. } 1.82 \\
-\frac{8.92}{\text { Diff. }}\end{array}\right|$ & $9 \cdot 65$ & 17 \\
\hline \multicolumn{7}{|c|}{ Red light (red glass No. 2).-3rd image. } \\
\hline Feb. 17,1880 . & $35 \cdot 0$ & $847 \cdot 6$ & $1 \cdot 012$ & $\mid \begin{array}{r}24 \cdot 78 \\
\text { Corr. } 3 \cdot 19 \\
\text { Diff. } 21 \cdot 59\end{array}$ & $21 \cdot 85$ & $\mathbf{3} \cdot \mathbf{3}$ \\
\hline Feb. 20, 1880 . & $39 \cdot 5$ & $801 \cdot 7$ & $1 \cdot 085$ & $\left|\begin{array}{r}23 \cdot 53 \\
\text { Corr. } 3 \cdot 19 \\
\text { Diff. } \overline{20 \cdot 34}\end{array}\right|$ & $22 \cdot 07$ & $4 \cdot 6$ \\
\hline$"$ & $39 \cdot 5$ & $801 \cdot 7$ & $\begin{array}{l}\text { 2nd image. } \\
1.085\end{array}$ & $\left|\begin{array}{r}15 \cdot 53 \\
\text { Corr. } 2 \cdot 35 \\
\text { Diff. } 13 \cdot 18\end{array}\right|$ & $14: 30$ & $1 \cdot 4$ \\
\hline
\end{tabular}


Table (continued).

\begin{tabular}{|c|c|c|c|c|c|c|}
\hline Series. & $\begin{array}{c}\text { Average } \\
\text { tempera- } \\
\text { ture, } t .\end{array}$ & $\begin{array}{c}\text { Average } \\
\text { pressure, } \\
\text { H. }\end{array}$ & $\begin{array}{l}\text { Correction, } \\
(1+a t) 760 \\
\mathbf{H}\end{array}$. & $\begin{array}{c}\text { Numbers } \\
\text { observed } \\
\text { and cor- } \\
\text { rections. }\end{array}$ & $\begin{array}{l}\text { Corrected } \\
\text { magnetic } \\
\text { rotations. }\end{array}$ & $\begin{array}{l}\text { Mean } \\
\text { devia- } \\
\text { tions. }\end{array}$ \\
\hline \multicolumn{7}{|c|}{ 1st image. } \\
\hline Feb. 20, 1880 & 39.5 & $\begin{array}{l}\text { millim. } \\
801 \cdot 7\end{array}$ & $1 \cdot 085$ & $\left|\begin{array}{r}9 \cdot 88 \\
\text { Corr. } 1.51 \\
\text { Diff. } \\
8 \cdot 37\end{array}\right|$ & $\int^{\prime} \cdot 08$ & $1 \cdot 8$ \\
\hline \multicolumn{7}{|c|}{ 1st image (red glass No. 1, deeper red). } \\
\hline " " & $39 \cdot 5$ & $801 \cdot 7$ & $1 \cdot 085$ & $\left|\begin{array}{r}9 \cdot 30 \\
\text { Corr. } 1 \cdot 50 \\
\text { Diff. } \overline{7 \cdot 80}\end{array}\right|$ & $8 \cdot 46$ & 0.9 \\
\hline \multicolumn{7}{|c|}{ GREEN LIGHT. -4th image. } \\
\hline Feb. 17, 1880. & $24 \cdot 4$ & $819 \cdot 2$ & $1 \cdot 012$ & $\left|\begin{array}{r}44 \cdot 72 \\
\text { Corr. } 6 \cdot 13 \\
-\overline{D i f f .38 \cdot 59}\end{array}\right|$ & $39 \cdot 05$ & $7 \cdot 5$ \\
\hline$" \quad "$ & $32 \cdot 2$ & $839 \cdot 5$ & $\begin{array}{l}\text { 3rd image. } \\
\mid \quad 1.012\end{array}$ & $\left|\begin{array}{r}34 \cdot 12 \\
\text { Corr. } 4 \cdot 85 \\
\\
\text { Diff. } 29 \cdot 27\end{array}\right|$ & $29 \cdot 62$ & $4 \cdot 5$ \\
\hline \multicolumn{7}{|c|}{ 2nd image. } \\
\hline Feb. 20,1880 & $41 \cdot 4$ & 8037 & 1.089 & $\left|\begin{array}{r}24 \cdot 6] \\
\text { Corr. } 347 \\
-\overline{\text { Diff.21.14 }}\end{array}\right|$ & $23 \cdot 02$ & $2 \cdot 9$ \\
\hline$"$ & $40 \cdot 5$ & $800 \cdot 8$ & $\begin{array}{l}\text { 1st image. } \\
1.090\end{array}$ & $\begin{array}{r}12 \cdot 99 \\
\text { Corr. } 2 \cdot 22 \\
- \\
\text { Diff. } 10 \cdot 77\end{array}$ & $11 \cdot 73$ & $1 \cdot 5$ \\
\hline \multicolumn{7}{|c|}{ BLUE LIGHT.—2nd image. } \\
\hline $\begin{array}{c}\text { Feb. 17, } 1880 . \\
",\end{array}$ & $\begin{array}{l}40.9 \\
40.9\end{array}$ & $\begin{array}{l}849 \cdot 5 \\
849 \cdot 5\end{array}$ & $\mid \begin{array}{l}1.012 \\
1.012\end{array}$ & \begin{tabular}{|}
$25 \cdot 64$ \\
$25 \cdot 53$ \\
Correction o \\
the glasses \\
uncertain.
\end{tabular} & & $\begin{array}{l}5 \cdot 3 \\
5 \cdot 4\end{array}$ \\
\hline & & & 1st image. & & & \\
\hline Feb. 20, 1880. & $42 \cdot 3$ & $793 \cdot 4$ & $1 \cdot 100$ & $\left|\begin{array}{r}15 \cdot 14 \\
\text { Corr. } 2 \cdot 58 \\
\text { Diff. } 12 \cdot 56\end{array}\right|$ & $13 \cdot 90$ & $1 \cdot 5$ \\
\hline
\end{tabular}


The slight correction due to the presence of 0.05 of air can be calculated with great precision. For example, we have for the fourth image-

\begin{tabular}{lrr} 
& \multicolumn{2}{c}{4 th image. } \\
White. & Green. \\
Mixture ....................... & $31 \cdot 28$ & 39.05 \\
0.05 of air .................... & 0.32 & 0.38 \\
Difference $=0.95$ olefiant gas & 30.96 & $38 \cdot 67$ \\
Pure olefiant gas .............. & 32.59 & $40 \cdot 70$
\end{tabular}

\section{Discussion of the Results obtained.}

\section{Verifications of the Method of Observation.}

The principle of the method employed by me in this work consisted, as we have seen above, in amplifying the phenomenon by causing the luminous rays to pass several times through the tube full of gas. It is evident that the numbers obtained for each reflected image must be proportionate to the number of passages made by the luminous rays through the apparatus. These numbers should therefore mutually test each other; and by dividing them by $3,5,7$, and 9 we ought to obtain numbers which would represent the magnetic rotation corresponding to a single passage through the tube. With the same luminous source and the same coloured screen these numbers should be constant; but we have seen above that the composition of the light which reaches the eye in order to form the different images varies with them; we ought, then, to find numbers regularly varying with the order of the images.

Strictly speaking, all the measurements ought to be effected at the distance which separates the mirrors; and when any other gas than air is in question, the column studied has not exactly the same length as the distance from the mirrors. But we have seen that, in the interval of 0.06 metre which separates the end of the tube from the mirrors, the magnetic intensity is very feeble; and the effect due to this slight difference in length must be regarded as absolutely unimportant, so that the verifying calculations can be applied even when the tube is full of any gas whatever. The slight differences between numbers which, for the same gas, correspond to a single passage of a pencil of rays of the same colour, are partly due to variations in the colour of the images, rather than to errors in the measurements. 


\begin{tabular}{|c|c|c|c|c|c|c|c|c|c|}
\hline \multirow{11}{*}{ 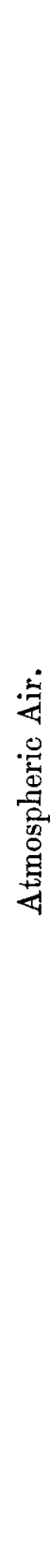 } & \multirow{2}{*}{ 胥 } & 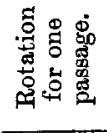 & & 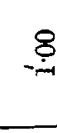 & 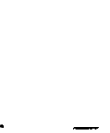 & & - & - & \multirow{2}{*}{-} \\
\hline & & 兽 & & $\overbrace{-\infty}^{8}$ & 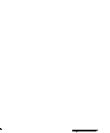 & & - & - & \\
\hline & ฐ્่ & 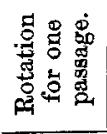 & 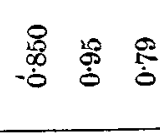 & $\vdots$ & 8 & & & 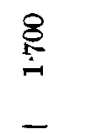 & $\underset{-}{\stackrel{\infty}{*}}$ \\
\hline & త్ర & 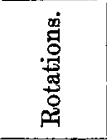 & 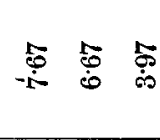 & 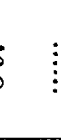 & $\stackrel{\mathscr{R}}{\dot{+}}$ & & & 的 & $\begin{array}{l}\overline{6} \\
\dot{\phi} \\
\end{array}$ \\
\hline & 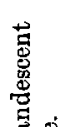 & 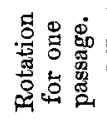 & 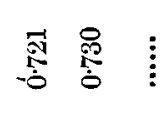 & $\vdots$ & $\ddot{6}$ & & :̊ & 葛 & $\stackrel{\stackrel{9}{\infty}}{\stackrel{\leftrightarrow}{-}}$ \\
\hline & 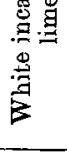 & 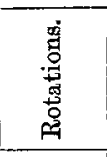 & 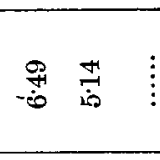 & $\vdots$ & 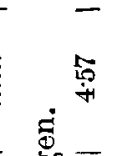 & हैं & - & 赵 & 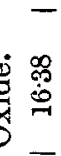 \\
\hline & $\stackrel{\dot{E}}{\circ}$ & 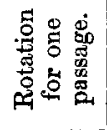 & 号 & & 8 & 莣 & $\frac{0}{0}$ & $\vdots \frac{\mathscr{D}}{0}$ & 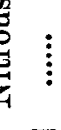 \\
\hline & 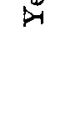 & 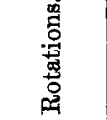 & $\begin{array}{ccc}\mathscr{P} \\
-\dot{\theta} & \vdots & \vdots\end{array}$ & $\vdots$ & $F$ & & $\vdots$ & $\vdots$ & $\vdots$ \\
\hline & ர் & 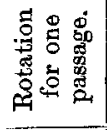 & 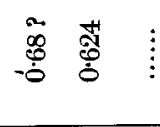 & $\vdots \vdots \vdots$ & है & & $\vdots$ & $\vdots$ & $\vdots$ \\
\hline & & 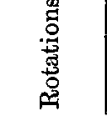 & $\begin{array}{ccc}\mathscr{9} & \vdots \\
-\overrightarrow{\dot{\theta}} & \vdots & \vdots\end{array}$ & $\vdots$ & 践 & & $\vdots$ & $\vdots$ & 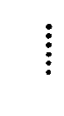 \\
\hline & & & 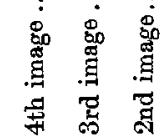 & 总 & 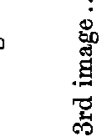 & & 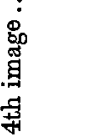 & 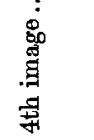 & 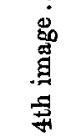 \\
\hline
\end{tabular}




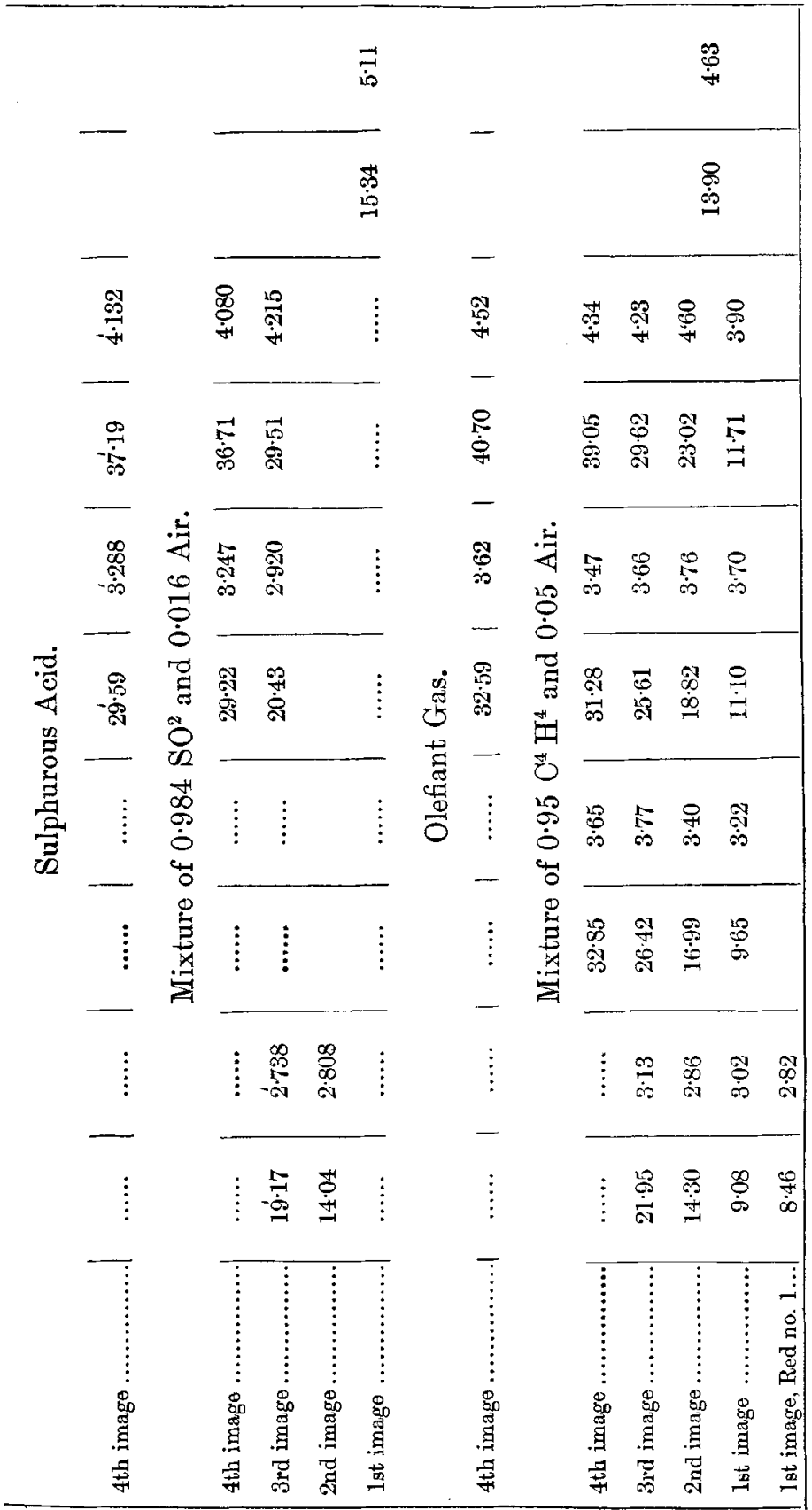


Almost the same results are obtained as with the glasses placed inside the first coil, especially with the white light. For example, if the rotations are compared with that which is deduced from the fourth image, we shall find that the rotations for a single passage of the white light are expressed by the following numbers:-

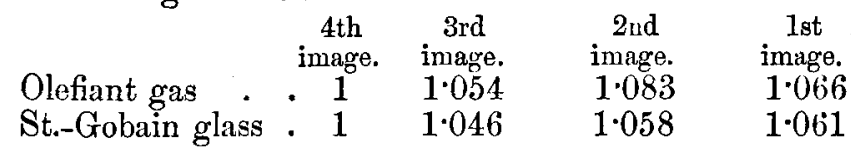

We see, then, that the divergences obtained between numbers which should be constant are partly due to the same cause -that is, to the difference in the colour of the various images.

If this is the case, the successive images with the white light ought to become more and more yellow, and the rotations should diminish from the first to the fourth. For the green light, on the contrary, the first image ought to be more yellow than the others, and the corresponding rotation more feeble. We find, in point of fact, that this deduction is confirmed by experiment. The absorption of the luminous rays by the coloured screens renders observations on the third and fourth images very difficult. It is necessary to increase the pressure of the oxygen from the blowpipe: the temperature of the line rises; but as the brilliancy increases it becomes more and more variable for very slight differences in temperature.

The want of regularity in the value of numbers deduced from the different images apprises us of these variations; nevertheless by taking the average of the numbers obtained, we see that we have results comparable with those deduced from observations made for the same colours with the carbon bisulphide.

\section{Dispersion of the Planes of Polarization of Luminous Rays having different Wave-lengths.}

The study of the phenomena of magnetic rotatory polarization in bodies comprises two parts:-

1st. The relative measurements of the rotations of the planes of luminous rays having different wave-lengths and traversing the same substance.

2nd. The comparison of the magnetic rotatory powers of various bodies for rays having the same wave-length.

I have demonstrated in the course of this memoir that the want of homogeneity in the luminous source compelled me to begin with the first of these studies - that is to say, to determine the relation of the rotations of the planes of polarization of rays of different colours. 
It has been shown that the luminous rays studied had not in each case the same wave-length, but that their average wave-length could be deduced from the magnetic rotation of the carbon bisulphide.

As the phenomenon has been exhaustively studied with regard to liquid bodies, such as carbon bisulphide, we can limit ourselves to comparing the relations of the magnetic rotations for the same colours with this body and with the different gases studied. The St.-Gobain glass, which has been made the object of special determinations in this memoir, can also serve for comparison.

By taking the average of the results obtained with each of the coloured screens employed, the results indicated in the following table were obtained; the unit to which the rotations for each substance were referred was the rotation obtained with the yellow light $D$, or the rotation deduced from the fourth white image.

Dispersion of the Planes of Polarization of Rays of different Wave-lengths.

\begin{tabular}{|c|c|c|c|c|c|}
\hline \multirow[b]{2}{*}{ Bodies. } & \multicolumn{5}{|c|}{ Magnetic rotations. } \\
\hline & Red. & $\mid \begin{array}{c}\text { Yellow D, } \\
\text { 4th white } \\
\text { image. }\end{array}$ & White. & Green. & Blue. \\
\hline Carbon bisulphide (liquid) & $0 \cdot 836$ & $1 \cdot 000$ & $1 \cdot 066$ & $1 \cdot 290$ & 1.480 \\
\hline St.-Gobain glass $\ldots . . . . \ldots \ldots . .$. & 0.845 & 1000 & 1.055 & 1.290 & $1 \cdot 51$ \\
\hline$\frac{1}{\lambda^{2}} \cdots \cdots \cdots \cdots \cdots \cdots \cdots \cdots \cdots \cdots \cdots$ & $0 \cdot 850$ & $1 \cdot 000$ & $1 \cdot 060$ & $1 \cdot 250$ & $1 \cdot 390$ \\
\hline Oxygen $\ldots . . . \ldots \ldots \ldots$ & & & & & \\
\hline Atmospherie air ............. & 0.860 & $\begin{array}{l}1.000 \\
1.000\end{array}$ & ...... & $1 \cdot 250$ & $1 \cdot 39$ \\
\hline $\begin{array}{l}\text { Nitrogen } \ldots \ldots \ldots \ldots \ldots \ldots \\
\text { Carbonic acid } \ldots \ldots \ldots \ldots \ldots \ldots\end{array}$ & $\ldots \ldots$ & $\begin{array}{l}1.000 \\
1.000\end{array}$ & .. & $1 \cdot 246$ & \\
\hline $\begin{array}{l}\text { Carbonic acid } \ldots . . . \ldots \ldots \ldots . . . \\
\text { Nitrous oxide }\end{array}$ & & 1.000 & ..... & $1 \cdot 197$ & \\
\hline Sulphurous acid ............ & 0853 & 1.060 & & 1.256 & \\
\hline Olefiant gas .................... & 0.849 & 1.000 & $1 \cdot 066$ & $1 \cdot 235$ & $1 \cdot 33$ \\
\hline
\end{tabular}

We see, first of all, that the statements of the rotations for two self-colours are nearly the same for liquids, gases, and solids. Oxygen, to which we shall return later, must be excepted. If the numbers contained in the summary (pp. 422, 423) be compared with those which were obtained by the glasses of the tube, it will be found that the numbers relative to the glasses of the tube are very nearly ten times those obtained for the air, and that in the two tables the same figures are sometimes reproduced for the same colours. I would again refer to the comparison made between the numbers obtained with the different white images.

These considerations enable us to see that the precision of 
the measurements can be carried very far, since it enables the variations in coloration of the successive images to be followed with gases as well as with a mass of glass. The average wave-length of the luminous pencil can then be approximately determined in each case and compared with the rotations obtained. The most simple means consists in making a graphical representation.

If the numbers inversely proportional to the squares of the wave-lengths distinguishing each image be taken as the abscisse, and the magnetic rotations observed for the ordinates, we see that the typical points of the determinations relative to the same substance approach very elosely to a right angle passing by the origin of the coordinates, which proves that the rotations are very nearly in the inverse ratio of the square of the wave-lengths, as may be verified by reference to the preceding table.

The numbers produced by the different images with different colours may each serve for the determination of an average right angle which, within the limits of the observations, represents the phenomenon with sufficient precision.

Briefly summarizing, we see that, for five of the gases studied, the magnetic rotation of the planes of polarization of luminous rays having different wave-lengths is very nearly in the inverse ratio of the squares of the wave-lengths of these rays. The slight value of the rotations observed did not allow me to ascertain whether these gases, like solids and liquids, diverge a little from this simple law in proportion as the rays become more refrangible.

The nitrous oxide gives a rather less deviation than the other gases. We may remark that, in order to make the numbers agree with those given by the other bodies, it would suffice to multiply the results by 1.05 ; and as this ratio 1.05 is exactly the ratio of the rays of white light to the rays of yellow light, we may conclude that the inequality is due to an increase of brilliancy in the luminous source at the moment of the experiment with the white light. This explanation appeared to me to be admissible; but if such were not the cause of the divergence observed, we may associate this fact with that presented by oxygen, and which I will now discuss.

Oxygen showed a remarkable anomaly. Previously, while studying the magnetic rotatory powers of various bodies with the yellow light, I had discovered that the presence of oxygen in a combination tended to diminish the rotatory power of the compound. I now find that gaseous oxygen has a feeble positive magnetic rotatory power, and that, in addition, it does not disperse the planes of polarization of rays of different colours as the other gases do. The numbers which relate to this body 
are very small, and the precision of the observations is much less than for the other gases. It is noticeable that this want of precision was characteristic of the experiments made with oxygen-although I always took the measurements with the same care, and although I studied this gas several times at different periods during our series of experiments. If the numbers found directly for the various colours be not corrected by the rotation of the glasses, it will be seen that they are very nearly equal to each other. In order to prove this fact, I took the precaution of making a large number of series, operating alternately with red and green rays; and I always found that the rotations were essentially the same.

Now, as the magnetic rotation due to the glasses is greater for the green rays than for the red rays, we should conclude from this that the oxygen would deflect the plane of polarization of the green rays less than that of the red rays, in opposition to the other gases studied up to this time. This body presents, then, a most curious exception; and it would be very important to establish this fact irrefragably. The numbers that I obtained do not as yet allow of it; but I anticipate soon being able to complete the first experiments required to do so.

However, it is easy to see that oxygen, if it does not present an inverse magnetic rotatory dispersion, would have at least a dispersion which is very nearly nil. The present experiments do not allow us to decide whether the rotations slightly augment or decrease with the refrangibility.

It is not uninteresting to consider the exceptional phenomenon of the magnetic properties of oxygen.

I have shown in previous researches that very magnetic bodies endowed with a negative magnetic rotatory power disperse the planes of polarization of light according to a different law from that which governs positive rotations. The ratios of the negative rotations are obviously the squares of the ratios which correspond to the positive magnetic rotations for the same luminous rays.

Now, it is extremely interesting to remark that the exception relative to oxygen coincides with the special magnetic properties of this gas. At present we cannot demonstrate that the coincidence which the two phenomena appear to show connects them one with the other. By referring to my former researches, it will be seen that it is possible to conceive the existence of a mixture of two substances, the one magnetic and the other diamagnetic, which would give rise to the same phenomenon as oxygen. This, however, is pure hypothesis; but it is interesting to consider it, especially when it relates to a body so singular as oxygen, which, on the one hand, is endowed with exceptional magnetic properties, and, on the 
other, gives rise to the very peculiar modification known as ozone. However, I propose to investigate more fully the cause of the anomaly just noticed.

III. Magnetic Rotations of Gases compared with Carbon Bisulphide for the Yellow Rays of Soda.

The relation above established between the magnetic rotations of the planes of polarization of rays of different colours and the wave-length of the corresponding light, enables us to determine the magnetic rotation relative to the yellow light of soda which corresponds to the rays $D$ in the solar spectrum. In order to effect this determination, use may be made of all the numbers obtained for the different colours, either by means of graphical representation, or by dividing each of them by the inverse ratio of the squares of the wave-lengths. In this way the following results have been obtained for the different gases (oxygen, which has already been considered, is excluded from the following table):-

Rotations for the Yellow Light D, deduced from Observations with Rays of different Colours.

Atmospheric Air.

Colour of the rays. $\begin{aligned} & \text { Numbers } \\ & \text { obtained. }\end{aligned}$ Mean. $\begin{gathered}\text { Mean } \\ \text { deviation. }\end{gathered}$

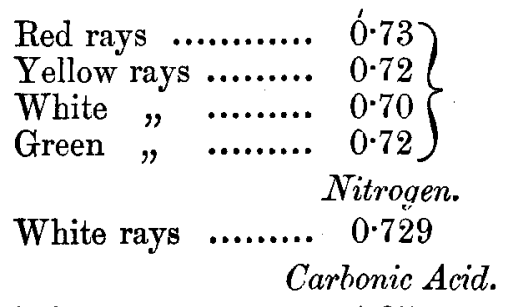

$\left.\begin{array}{llll}\text { White rays } & \ldots \ldots . . . & 1.37 \\ \text { Green } " & \ldots . . . . & 1.36\end{array}\right\} \quad 1.365 \quad$ Is 0

Nitrous Oxide.

$\left.\begin{array}{lll}\text { White rays } & \ldots . . . . . . & 1.82 \\ \text { Green }, 1 & \ldots . . . . & 1.74\end{array}\right\} \quad 1.78 \quad \frac{1}{40}$

Sulphurous Acid.

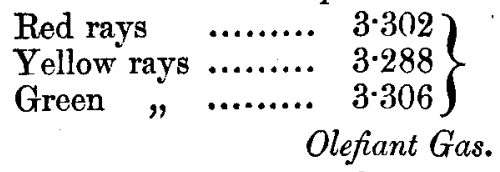

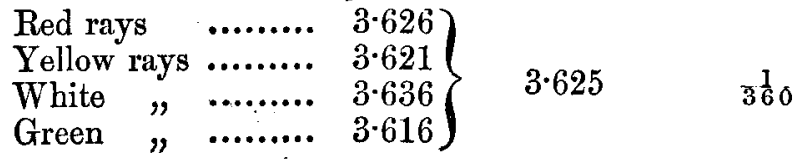


These numbers correspond to a single passage of the luminous rays through the tube; we see with what precision they mutually test each other. By dividing these numbers by the rotation obtained for carbon bisulphide under the same conditions, and which was found to be equal to $4520^{\prime}$, the following table is obtained:-

Magnetic Rotations of Gases compared with liquid Carbon Bisulphide (yellow light D).

\begin{tabular}{|c|c|c|}
\hline Gas. & $\begin{array}{c}\text { Rotation for one } \\
\text { passage. }\end{array}$ & $\begin{array}{l}\text { Rotations com- } \\
\text { pared with carbon } \\
\text { bisulphide. }\end{array}$ \\
\hline Oxygen & 0.663 & 0.000146 \\
\hline Air $\quad \ldots . .$. & 0.720 & 0.000159 \\
\hline Nitrogen & $0 \cdot 7: 29$ & 0.000161 \\
\hline Carbonic acid & 1.365 & 0.000302 \\
\hline Nitrous oxide & 1780 & 0.000393 \\
\hline Sulphurous acid .... & $3 \cdot 300$ & 0.000730 \\
\hline Olefiant gas. & $3 \cdot 625$ & 0.000802 \\
\hline
\end{tabular}

In the course of the experiments an occasion offered of verifying the preceding numbers.

We have seen how the determination of the magnetic rotation of the glasses in the tube inside the first coil was effected. This rotation may be compared with that of the gases. Now it happens that for air the comparison is immediate ; the rotation of the glasses (say 1 centim. of crown glass) is equal to ten times the rotation of 3 metres of air (say to 3000 centim. of air submitted to the same magnetic influence). The relation of the rotations is then

$$
\frac{1}{3000}=0.00033 \text {. }
$$

Now in my former researches I found that the magnetic rotatory power of crown glass for the yellow light was $0 \cdot 48$ of that of carbon bisulphide. By adopting this number, which is independent of our present experiments, we should find for the rotatory power of air $0.000158^{*}$.

* Since the time when I began these researches, MM. Kundt and Röntgen have published numbers relative to several gases. The only ones common to our researches are oxygen and air. The numbers given by these authors in their first memoir (Wiedemann's Annalen, t. viii. p. 278 ) are too large, because they have compared the rotations obtained directly with white light for gases, and with yellow light D for carbon bisulphide. For oxygen the number that $I$ find is identical with that which they have given for high pressures. The agreement is, no doubt, owing to the fact that oxygen has no sensible rotatory dispersion, and that the errors which they committed respecting the refrangibility of light became then unnoticed. In a second memoir the same authors have

Phil. Mag. S. 5. Vol. 12. No. 77. Dec. 1881. 2K 


\section{Relation between the Magnetic Rotatory Powers of Gases and their Indices of Refraction.}

I have demonstrated that a remarkable relation exists between the rotations of the planes of polarization of light traversing non-magnetic solid and liquid bodies and the indices of refraction of these bodies for the same luminous rays. It was of the greatest importance to prove whether such a relation still existed in the gaseous state; and I took the opportunity of saying at the beginning of this memoir, that I was guided by these considerations in the construction of the apparatus employed in the researches. The experiments just described have justified my expectations.

When the magnetic rotations obtained for the different gases are compared with the indices of refraction of the latter for the yellow light of soda, it is seen that the rotations increase regularly with the indices of refraction. In the table which follows, I have placed opposite to the magnetic rotations of the gases their indices of refraction:-

Magnetic Rotations of Gases compared with liquid Carbon Bisulphide.

\begin{tabular}{|c|c|c|c|c|c|}
\hline Gas. & $\begin{array}{c}1 . \\
\text { Magnetic } \\
\text { rotatory } \\
\text { powers, } \\
\mathbf{R} .\end{array}$ & $\begin{array}{c}2 . \\
\text { Magnetic } \\
\text { rotations. }\end{array}$ & $\begin{array}{c}3 . \\
\text { Indices of } \\
\text { refraction, } \\
n .\end{array}$ & $\begin{array}{c}4 \\
(n-1)^{2}\end{array}$ & $\begin{array}{c}5 . \\
\frac{\mathrm{R}}{n^{2}\left(n^{2}-1\right)}\end{array}$ \\
\hline Oxygen .. & 0.000146 & 0.918 & $1 \cdot 0002706$ & $0 \cdot 850$ & $0 \cdot 269$ \\
\hline Air..... & 0.000159 & 1.000 & 1.0002936 & 1.000 & 0.277 \\
\hline Nitrogen & 0.000161 & 1.012 & 1.0002977 & 1.027 & $0 \cdot 274$ \\
\hline Carbonic acid & 0.000302 & 1.900 & $1 \cdot 0004544$ & $2 \cdot 393$ & 0.332 \\
\hline Nitrous oxide & 0.000393 & $2 \cdot 471$ & $1 \cdot 0005159$ & 3.086 & $0 \cdot 381$ \\
\hline Sulphurous acid... & 0.000730 & $4: 591$ & 1.0006650 & 5.130 & 0.548 \\
\hline Olefiant gas ...... & 0.000802 & $5 \cdot 044$ & $\begin{array}{l}\text { (Dulong) } \\
1 \cdot 0006780 \\
\text { (Dulong) }\end{array}$ & $5 \cdot 327$ & 0.590 \\
\hline
\end{tabular}

In order to make a comparison between the numbers in the

given smaller numbers than those previously published; and the results at which they arrived do not agree any better with mine. The number that they attribute to air $(0.000127)$ is identical with that which I had previously published in a work on atmospheric polarization (Annales de Chimie et de Physique, t. xix.). I observed at the time that this number only approximated withm two or three tenths of its value; it results from the present memoir that it was too little by 0.00003 . 
first column and those in the third, we may construct a curve by taking the indices as the abscissæ and the rotations as the ordinates : in this way a curve of great regularity is obtained, whose form recalls that which we obtained under analogous conditions with liquid and solid bodies (fig. 5).

By seeking a simple function of the index, which varies proportionately to the rotations observed, we easily see that the ratios of the function $(n-1)^{2}, n$ being the index of refraction, follow very nearly those of the magnetic rotations. These appear in columns 2 and 4 of the preceding table. However, it does not seem that this formula is the complete expression of the relation between the magnetic rotatory powers of bodies and their indices of refraction. We had already observed that it did not suffice for the various peculiarities of the phenomenon in solids and liquids; and it is easy to see that it does not account for the relation of the magnetic rotatory powers of bodies in the liquid and gaseous conditions.

In my previous researches, I had been led to adopt the expression $n^{2}\left(n^{2}-1\right)$ as approximately representing the statements of the magnetic rotatory powers of the various solid and liquid bodies that had been studied. I had discovered that the relation of the magnetic rotation $R$ to the function $n^{2}\left(n^{2}-1\right)$ varied very little when compared with the great variations of the magnetic rotations of one body and another.

The unit adopted was the magnetic rotation of liquid carbon bisulphide; and the values of the expression $\frac{\mathrm{R}}{n^{2}\left(n^{2}-1\right)}$ (generally about 0.25 ) varied between 0.10 and $0.50 *$. These values are indicated in column $\mathbf{5}$ of the preceding table. The numbers obtained are the same as for various solid and liquid bodies. Thus, although the magnetic rotations are 10,000 times smaller than in liquid bodies, the variations in the function $n^{2}\left(n^{2}-1\right)$ are always of the same relative order of size as those of the magnetic rotations.

It ought, however, to be observed that the numbers in the fifth column of the preceding table increase regularly with the indices of refraction, which tends to prove that the formula $n^{2}\left(n^{2}-1\right)$ is only an approximate expression of the phenomenon, which answers sufficiently well for the properties of non-magnetic solid and liquid bodies, but which might diverge from experiment when the values of the index of refraction became very small, as in the case of gases.

The variations of the expression $\frac{\mathrm{R}}{n^{2}\left(n^{2}-1\right)}$ with gases do

* See the researches quoted above. $2 \mathrm{~K} 2$ 
not, however, exceed the limits of those which are presented by solid and liquid bodies; and this study must be extended to a much greater number of gases before we are able to decide whether these variations are not simply characteristics of the physical and chemical constitution of gases, as we have discovered in regard to other substances.

Some interesting remarks may be made on this subject. The numbers given above enable us to compare the magnetic rotatory powers of gaseous sulphurous acid with that which it possesses in a liquid state. M. de la Rive found for liquid sulphurous acid a magnetic rotatory power variable with the temperature, and which at about $12^{\circ}$ is nearly 0.382 . But the index of refraction of this body has not been accurately measured. Faraday merely says that the index is the same as that of water ; on this hypothesis we should find that the ratio $\frac{\mathrm{R}}{n^{2}\left(n^{2}-1\right)}$ is $0 \cdot 277$-that is to say, exactly the half of the number found with the gaseous body. Is this statement a mere conjecture, or is it the expression of a more general fact?*

An analogous result is observed on comparing with the number obtained for oxygen the numbers given by certain highly oxygenated liquids, such as nitric and sulphuric acids, \&c. $\frac{R}{n^{2}\left(n^{2}-1\right)}$ is about 0.11 for these bodies, while it is 0.27 with gaseous oxygen. Finally, we may connect with these facts an observation relative to various salts (chloride of sodium and chloride of potassium) endowed with a positive rotatory power. Their magnetic rotatory power is less in a crystalline condition than in solution.

These various remarks would then tend to show that the positive rotatory power of a body is so much the greater in relation to its index of refraction as the particles of the bodies are further apart, and that it increases on passing from a liquid to a gaseous state.

This question requires a special study, which could not form part of the present work, but to which I intend to return at some future time. If we are not absolutely anthorized to assert that the function $n^{2}\left(n^{2}-1\right)$ plays the same role for the magnetic rotations of gases as for other substances, this re-

* In a recent article (Journal de Physique, August 1880) M. E. Bichat has studied sulphurous acid, both liquid and gaseous. He found for the magnetic rotation of the liquid a number very near to that of $M$. de la Rive; for the index of refraction of the same body he gives the number 1.34 ; but the magnetic rotatory power that he attributes to the gas differs very much from that deduced from my experiments. 
markable fact is nevertheless established,--that the magnetic rotatory powers of bodies are closely connected with their index of refraction $n$, and that the variations of the function $n^{2}\left(n^{2}-1\right)$ are of the same order and magnitude as those of the magnetic rotations of bodies in the solid, liquid, and gaseous conditions.

In concluding this memoir, I think it necessary to lay stress on the theoretical interpretation of the formula $\frac{n^{2}\left(n^{2}-1\right)}{\lambda^{2}}$, which, according to these researches, seems to intervene in the expression of the magnetic rotatory power of bodies. It can be written $\frac{n^{2}-1}{\left(\frac{\lambda}{n}\right)^{2}}$; under this form the denominator represents the wave-length of the luminous vibratory movement inside the body studied. The rotation of the plane of polarization of the light would be therefore in the inverse ratio of the square of this wave-length, and would be proportionate to the expression $n^{2}-1$, which, according to the theoretical views of Fresnel and the experiments of M. Fizeau, measures the partial influence of the undulatory movement of a body on the luminous waves.

It is interesting to note that experiment leads to this same expression to measure the action of magnetism on the propagation of luminous vibrations through bodies, thus establishing a new relation between a mechanical effect and the effects of electromagnetic influence. Perhaps this influence of luminous waves on the vibratory movement so well studied is of a kind to inform us as to the mode of motion which manifests itself to us under the form of electricity and magnetism.

\section{Conclusion.}

The results established in this memoir are as follows:--

1st. Bodies in a gaseous condition possess, like solid and liquid substances, the property of deflecting the plane of polarization of luminous rays passing through them when they are submitted to the influence of magnetism.

2nd. The magnetic rotations of the planes of polarization of rays of different wave-lengths traversing the same gas (oxygen excepted) are generally very nearly in the inverse ratio of the squares of the wave-lengths of the luminous rays considered.

3rd. The magnetic rotatory powers of gases can be compared with that of liquid carbon bisulphide, and consequently with those of other solid and liquid bodies. 
We have discovered in gaseous bodies, as it had been formerly observed for other substances, a remarkable relation between the indices of refraction and the magnetic rotatory power of rays having the same wave-length.

4th. Finally, oxygen presents an anomaly which seems connected with the exceptional magnetic properties of this gas.

LII. On the Beats of Mistuned Consonances.

To the Editors of the Philosophical Magazine and Journal. Gentlemen,

T $N$ your November number, in a paper by Professor $\mathrm{S}$. $P$. 1 Thompson on Binaural Audition, there occur some references to my recent work. While it is gratifying that the work should have attracted Prof. Thompson's attention, it is rather disheartening to find that he has failed for the most part to grasp its purport. I am obliged to him for his remarks, as, if he has failed to understand it, I dare say a good many other people will have done the same; and it affords me the opportunity of putting two or three points in a clear light. I will take the passages I have to observe upon in order.

Page 352. Halfway down, the word subjective is underlined and a note appended. In the note there is first an objection to my use of the word. I have never believed much in the advancement of clearness by the employment of words very strictly defined. In speaking of any particular matter, it seems to me generally necessary and sufficient to give such descriptions as shall leave no doubt of the meaning. This I have amply done. Over and over again I have described the subjective phenomena as being such as originate within the ear itself. Whether this is the strictly philosophical sense is to me immaterial. I took the use of the word from Helmholtz (Ellis's 'Helmholtz,' p. 234, foot of page ; 4th German edition, p. 259, top of page). I think it is there used in the sense in which I use it*. I may put the matter otherwise thus:- In a binary combination $a \sin \mathrm{A}+b \sin \mathrm{B}$ I find the term lower in pitch $(a \sin A)$ subject to a variation of the coefficient $a$. Does this variation arise before or after the arrival of the combination at the gates of the ear? If before, I call the variation objective; if after, subjective. I will not repeat the argument from resonators; it is sufficiently stated in my paper.

Prof. Thompson then makes an objection which precisely

* Viz. as opposed to the objective origin of combination-tones in instruments described a little further on. 